\title{
Das nossas ciências ao diálogo intercientífico para a sustentabilidade alimentar e o desenvolvimento sustentável ${ }^{1}$
}

\author{
From our science to the interscientific dialogue for food sustainability and sustainable \\ development
}

\author{
Freddy Delgado ${ }^{2}$ \\ Stephan Rist ${ }^{3}$ \\ Johanna Jacobi ${ }^{4}$ \\ Mayra Delgado 5
}

\begin{abstract}
Resumo
Este artigo discute as ciências endógenas como um sistema de conhecimentos que pode contribuir para a segurança e a soberania alimentar. Toma como premissa fundamental o reconhecimento de que todos os sistemas de conhecimentos milenares do mundo são ciências com suas próprias epistemologias e ontologias e isto implica em diferentes visões de vida e valorações, como é o caso dos conceitos de alimento e medicina. O objetivo deste artigo é analisar e promover marcos teóricos e metodológicos que levem ao diálogo intercientífico de saberes entre os diferentes sistemas de conhecimento do mundo, considerando o pluralismo epistemológico e o surgimento e/ou recriação de paradigmas das ciências e o desenvolvimento, e propondo delineamentos a partir da praxis para fortalecer o corpus cognitivo das ciências endógenas que aportem à sustentabilidade alimentar e ao desenvolvimento sustentável. Pode-se afirmar que o diálogo de saberes que parte da revalorização da sabedoria das nações e povos indígenas camponeses do mundo (que chamamos de intraculturalidade) e a transdisciplinaridade (acadêmica), tem sido a base para sustentar um marco teórico-conceitual e metodológico que permite aportar à construção de novos paradigmas das ciências e o desenvolvimento que se concretiza no diálogo intercientífico.
\end{abstract}

Palavras-chave: Segurança e Soberania Alimentar; Ciências endógenas; Desenvolvimento Sustentável.

\begin{abstract}
This article discusses the endogenous science as a system of knowledge that can contribute to the security and sovereignty food. A fundamental premise for this is there cognition that all systems of ancient knowledge of the world are sciences with their own epistemologies and ontologies and this implies different visions of life and ratings as in the case of the concepts of food and medicine. The aim of the article is to analyze and promote methodological frame works to contribute to the dialogue of knowledge and interscientific between different knowledge systems in the world,

\footnotetext{
${ }^{1}$ Este artigo foi adaptado e modificado a partir de outras duas publicações: Delgado, Escobar y Guarachi In: Delgado y Ricaldi (2012); e capítulos 2 e 6 de Delgado y Delgado (2014).

2 Professor e pesquisador da Facultad de Ciencias Agrícolas, Pecuarias y Forestales, Universidad Mayor de San Simón (UMSS-FCAPyF). Contato freddydelgado@agruco.org

${ }^{3}$ Professor e pesquisador do Centre for Development and Environment (CDE) da Universidade de Berna, Suíça.

4 Doutora sobre "Resiliencia en el cultivo de cacao orgánico en Bolivia", e pós-doutorado em "Agroforestería".

${ }^{5}$ Licenciada em Sociologia.
} 
considering the epistemological pluralism and the emergence and / or recreation paradigms of science and development, proposing guidelines from the praxis to strengthen the cognitive corpus of endogenous sciences that contribute to food sustainability and sustainable development. We can say that the dialogue of knowledge, that part of the appreciation of the wisdom of nations and indigenous peasants in the world (which has been called thein traculturality) and transdisciplinarity (more on academics) have been the basis to support a conceptual and methodological framework that allows contribute to the construction of new paradigms of science and development as embodied in the interscientific dialogue.

Key words: Security and Sovereignty Food; Endogenous science; Sustainable Development.

\section{Introdução}

Há uma crise generalizada no mundo do modelo de desenvolvimento capitalista norteamericano surgido como proposta no pós-guerra e que priorizou o crescimento econômico e o bem-estar material. Este modelo não funcionou, além de ter aprofundado a pobreza e a desigualdade social afetando a sustentabilidade da vida no planeta em razão de acelerar a deterioração ambiental e uma perda de valores éticos.

Esta crise de civilização está claramente identificada no ocidente em que a ciência e a tecnologia tem desempenhado um papel fundamental em todo este processo que coloca em risco a vida no planeta. Por isso, afirmam Sevilla e Alonso (1994, p.25): “cualquier definición de sostenibilidad es necesario, de hecho, que tenga en cuenta las dimensiones cultural y estructural, ya que de lo contrario, alentará las destructivas tendencias del despotismo urbano - industrial en que nos ha introducido la dinámica del capitalismo."

Desta forma, o desenvolvimento em sua versão economicista ou agora em sua versão "sustentável” deu hegemonia global a uma genealogia da história puramente ocidental, limitando os povos indígenas originários e trabalhadores de outras regiões do mundo a oportunidade de criar suas próprias concepções e visões de mundo e do cosmos e que permitisse a recriação e geração permanente de conhecimentos locais e globais, fortalecendo suas culturas, seus saberes, suas tecnologias, seus métodos, suas ferramentas e suas ciências a partir de distintas realidades e percepções de vida.

Atualmente surge em diferentes continentes e regiões do mundo, culturas e povos antigos como a chinesa, indiana, maya, andina, mapuche dentre outras - a necessidade de revalorizar e recriar sua sabedoria ancestral entendida como o saber ou conhecimento que transcende o tempo e o 
espaço e que podem advir das nações indígenas originárias e camponesas em que a vida espiritual é fundamental e está articulada à vida social e à vida material. Estes três pilares inter-relacionadas constituem a base do centro universitário Agroecología Universidad Cochabamba (AGRUCO) ${ }^{6} \mathrm{em}$ seus programas de pesquisa, extensão e formação.

Esta sabedoria ancestral é aquilo que Haverkort, Delgado, Shankar y Millar (2013, p. 20) tem chamado, depois de quase quinze anos de pesquisas nos programas internacionais COMPAS y CAPTURED de ciências endógenas. Uma conclusão geral nesta perspectiva de análise é que o diálogo entre as ciências endógenas e certas comunidades científicas ocidentais modernas estão em construção teórica e metodológica de seus fundamentos e suas possíveis complementaridades e confrontações.

\section{Do desenvolvimento sustentável e a ciência ocidental moderna para um diálogo de saberes e intercientífico}

É em meados do século XX, depois da segunda guerra mundial, que o conceito de desenvolvimento começa a aparecer fortemente como parte do discurso da modernidade com o presidente Truman dos Estados Unidos. Recordemos que durante o século XX, o discurso e a prática do desenvolvimento e a ciência ocidental moderna como seu principal instrumento estavam voltados para buscar alternativas para melhorar exclusivamente os incrementos econômicos e a partir da compreensão que a vida material e o bem-estar material é que gerariam melhorias na qualidade de vida. A preocupação com a ética e a espiritualidade foi obviamente esquecida e aqueles que se preocupavam com estas questões foram tachados de fundamentalistas.

No campo agropecuário, a revolução verde, como alternativa desenvolvimentista e resposta científica para a produção de alimentos fundamentada na agroindústria, nos pacotes tecnológicos e nos agrocapitais implicou a vinculação definitiva dos sistemas alimentares produtivos e a

\footnotetext{
6 A experiência institucional de AGRUCO data de 1985, a partir de um projeto experimental da UMSS em convênio com a Agência Suíça de Cooperação para o Desenvolvimento (COSUDE). Nestes 30 anos de atividade, um aspecto fundamental que definiu o perfil institucional foi a agroecologia, o diálogo de saberes, a investigação participativa revalorizadora e nos últimos 10 anos, a transdisciplinaridade e o diálogo intercientífico com a participação do autor principal como coordenador na América Latina dos programas internacionais COMPAS y CAPTURED. Este perfil institucional foi a base para uma reflexão teórica-conceitual e metodológica questionadora da visão fortemente materialista e capitalista que impera no mundo, que no entanto atenta contra o equilibrio natural e a reprodução dos processos vitais.
} 
dependência às sementes melhoradas, agroquímicos e matérias primas que procediam das emergentes empresas agroindustriais e bioquímicas. Hoje esta submissão se aprofunda com as sementes transgênicas e toda a engenharia genética manejada por empresas trasnacionais.

Esta proposta capitalista agressiva foi afetando e continua a afetar seriamente a subsistência da agricultura camponesa baseada na diversificação produtiva e no uso de insumos locais que foram durante séculos a base da alimentação acumulando experiências, técnicas, tecnologias e saberes.

A segurança alimentar foi seriamente afetada e somente recentemente, em 1969, é que a Organização das Nações Unidas para a Alimentação e a Agricultura (FAO) a definiu como prioridade. Toda a rica experiência das comunidades indígenas camponesas do mundo, e especialmente as latino-americanas, na produção de alimentos e a relação com a natureza foram consideradas obsoletas e descartadas como alternativas para o desenvolvimento agropecuário.

Devido aos efeitos ambientais e sociais devastadores que geraram as políticas pródesenvolvimentistas no final da década de 80 e início dos anos 90, as Nações Unidas organizaram a Conferência Internacional de Meio Ambiente e Desenvolvimento conhecida como a Cúpula Rio. A Conferência ocorreu no Rio de Janeiro em 1992 e acabou dando origem ao "desenvolvimento sustentável" que questionava seriamente a viabilidade e sustentabilidade dos resultados da revolução verde e o caráter do desenvolvimento econômico.

De fato, nos círculos acadêmicos do mundo, e na América Latina em particular, se considerava que a única possibilidade para sair do "subdesenvolvimento" era pela modernização total da agricultura. As propostas e experiências da agroecologia, da agricultura camponesa e de todos aqueles que atuavam e pensavam de maneira diferente foram consideradas retrógradas e inimigas do desenvolvimento.

Em algumas universidades e faculdades de agronomia, pecuária, pesca e ciências florestais, o desenvolvimento agropecuário segue baseado no enfoque da revolução verde e na última década, nas sementes transgênicas. Assumir este novo enfoque de desenvolvimento sustentável e da agroecologia como proposta para a produção de alimentos e para a vida, segue, no entanto, como uma utopia realista.

Assim, a revalorização dos saberes ancestrais e os saberes locais, camponeses e indígenas, especialmente na agricultura, na medicina, na elaboração de alimentos e na saúde, não foi uma prioridade na maior parte das universidades latino-americanas existindo pouquíssimas experiências no centro universitário AGRUCO na Bolívia, no projeto de tecnologias andinas (PRATEC) no Perú 
ou a rede de patrimônio biocultural do Concejo Nacional de Ciencia y Tecnología (CONACYT) no México.

Igualar processos de diálogo de saberes entre a agricultura indígena camponesa e a agroecologia com a agricultura industrial moderna foi impossível devido à soberba desta última em crer-se como a única e verdadeira alternativa para o desenvolvimento, a eliminação da pobreza e a fome. Soberba que ainda continua pelo poder do capitalismo transnacional que pode pagar por cientistas, políticos e consciências.

A ciência como todo conhecimento racional e empírico baseado na demonstração, experimentação e na observação científica foi a linha de demarcação em que o racional, o objetivo e o quantificável tornaram-se equivalente à visão ocidental moderna, rechaçando ou ignorando outras racionalidades que também consideravam o subjetivo, o intuitivo e o qualitativo.

$\mathrm{Na}$ Bolívia, se assumiu que o desenvolvimento científico e tecnológico surgiu a partir da invasão espanhola em 1532 e da criação das primeiras universidades (em Chuquisaca em 1824 a Universidad San Francisco Xavier, em 1830 em La Paz a Universidad Mayor de San Andrés, e em 1832 em Cochabamba a Universidad Mayor de San Simón). Este processo, porém não considerou todo o avanço científico e tecnológico que deixaram as civilizações andinas como quechua e a aymara.

A este respeito, Condarco (1981, p.326), em seu livro premiado pela Academia Nacional de Ciencia de Bolivia em 1978 "Historia de la ciencia en Bolivia: Historia del saber científico en Bolivia", destaca que "la ciencia en Bolivia ha desempeñado, de manera harto predominante, un papel pasivamente receptivo en la mayor parte de los campos de investigación; y de manera especial, en el campo de las ciencias de la naturaleza: en astronomía, física, química, biología, medicina, etc.”. Este importante livro quase desconhecido pelos cientistas bolivianos demonstra o avanço do conhecimento antes da chegada dos espanhóis em 1532.

A ciência positivista e neopositivista e o desenvolvimentismo se interiorizaram nas universidades públicas e a sua hegemonia perdura do século XIX até os dias atuais. Com a ideia da modernização como razão de existência da educação superior, poucos centros de formação e investigação, como o AGRUCO na Bolívia, desenvolveram a difícil tarefa de trabalhar com inovações e alternativas que fossem diferentes àquelas criadas pela ciência na visão ocidental moderna e que se replicaram em todos os âmbitos e fundamentalmente na classe média e no setor urbano. 
Os indígenas camponeses, suas sabedorias e conhecimentos ancestrais foram marginalizados da vida colonial e da república até 1952, ano da reforma agrária, em que também surgiu uma proposta política alternativa ao capitalismo mundial com o socialismo como transição ao comunismo, baseado na famosa obra de Karl Marx sobre o capital. Jovens universitários da época carregaram esta bandeira política eurocêntrica, mas sem reconhecer a sabedoria ancestral dos indígenas camponeses que moravam no território boliviano.

Com a abertura da democracia representativa em 1982 e a implementação do modelo neoliberal em 1985, a situação se tornou ainda mais dramática. A tendência de privatizar a educação superior, a generalização e inovação do conhecimento em função do desenvolvimento empresarial, a internalização dos valores do mercado como a competitividade, a eficiência e a eficácia no perfil dos novos profissionais, o impulso e fomento de carreiras profissionalizantes e funcionais ao mercado acabaram liquidando qualquer pensamento progressista e ação científica revolucionária que fosse contestatória aos propósitos do capitalismo internacional e à ciência ocidental moderna.

Foram tempos em que a universidade do povo e para o povo foi o 'slogan' de estudantes universitários dos anos 70 e 80 como proposta contestatória aos governos ditatoriais, servis ao capitalismo internacional. Não era mais do que um slogan incongruente com a realidade, porque na vida diária da universidade, as políticas neoliberais impostas a partir de 1985 pelo Banco Mundial e Fundo Monetário Internacional, configuraram a academia e a institucionalidade das universidades públicas, criando paralelamente universidades privadas para ir substituindo o ensino superior do estado.

De alguma forma, esta situação teve uma mudança fundamental, ainda que, não suficiente, com a ascensão do primeiro presidente indígena da Bolívia em 2005, a Constituição Política do Estado em 2009 e a lei de Educação ‘Avelino Avelino Siñaniz y Elizardo Pérez', aprovada em dezembro de 2010, que reconheceu a intra e interculturalidade como aspectos fundamentais a serem considerados na educação em geral. Nos tópicos 3 e 4 se explorará a complementaridade entre os dois diferentes tipos de conhecimentos e saberes que existem, valorizando a cosmovisão das culturas indígenas originárias camponesas incentivando a interação da intra e interculturalidade e o plurilinguismo na formação integral para alcançar o "Viver Bem”. 


\section{Elementos para caracterizar as ciências dos povos indígenas originários ou ciências endógenas}

Os resultados enviesados, direcionados e, às vezes, pouco relevantes que geraram a ciência eurocêntrica da pesquisa, não permitiram contribuir com o fortalecimento de uma ciência para o desenvolvimento sustentável e a sustentabilidade alimentar, que permitisse inovações reconhecendo as contribuições de todas as nações e povos do mundo. Os esforços realizados, tampouco contribuíram com a redução da fome e da pobreza material no mundo, dando lugar a uma pobreza maior não só material, mas também social e espiritual, colocando em questão a suposta neutralidade da ciência.

Estas inovações devem partir da revalorização da sabedoria ancestral das nações indígenas originárias que comprovaram em todo o processo histórico da humanidade suas contribuições à sustentabilidade do planeta e foram, durante séculos, a base da sustentabilidade alimentar.

O surgimento das experiências da pesquisa-ação participativa e revalorizada nos últimos 30 anos, permitiram o surgimento de novos paradigmas das ciências e o desenvolvimento em cada país e continente. Esta vivência trouxe uma visão global, por meio do Programa Internacional "Comparando y Apoyando el Desarrollo Sostenible" (COMPAS) desde o ano de 1997 até o ano de 2012 e quase paralelamente, desde 2008 a 2013, com o programa internacional para a Construcción de Capacidades y Teorías en Universidades y Centros de Investigación para el Desarrollo Sostenible Sustentable (CAPTURED).

Estes programas, entre outras atividades, priorizaram a formação e a autoformação de jovens, entendida como a atualização dos conhecimentos e a aquisição de novas capacidades e qualificações, mas também perseguem a realização e o desenvolvimento espiritual deixado pelos ancestrais andinos. É uma tarefa que terá que prolongar-se ao longo de toda a vida cotidiana, que envolve de forma indivisível ao indivíduo com sua comunidade e que através do desenvolvimento sustentável busca o "Viver Bem" como proposta alternativa ao desenvolvimento capitalista imperante.

Hoje, podemos afirmar que estas correntes ou escolas de pensamento e experiências, que sabemos que não são únicas, deram seus primeiros passos. Há ainda os passos dados por movimentos sociais e intelectuais orgânicos, cujas perspectivas são favoráveis dada a crise global do capitalismo, que inclui a mudança climática, a crise financeira, a crise do conhecimento hegemônico e a crise alimentar. 
É importante ressaltar que os elementos de caracterização das ciências das nações indígenas originárias apresentadas a seguir, correspondem à sistematização do Centro Universitário AGRUCO de toda a sua experiência de mais de trinta anos de trabalho com comunidades indígenas camponesas, principalmente na região andina da Bolívia e que mediante o diálogo de saberes, a intra e interculturalidade e a transdisciplinaridade, e não diretamente a partir de uma visão indígena, buscou contribuir com a construção de marcos conceituais para a sustentabilidade alimentar e o desenvolvimento sustentável na perspectiva do "Viver Bem". Neste sentido, iremos recorrer à ontologia, gnosiologia e epistemologia, como categorias que nos ajudam a sistematizar esta experiência.

Conscientes das limitações que isto implica e para que nos aprofundemos no conhecimento das ciências endógenas, mas, ao mesmo tempo, seguros da necessidade de começar com o debate, propomos os elementos apresentados na sequência a partir de "nossas ciências".

As características ontológicas dos saberes ancestrais estão emolduradas por uma visão de mundo ou cosmovisão que estabelece que "tudo tem vida", logo tudo é sagrado e com o mesmo nível de importância para a reprodução da vida. Para a cosmovisão indígena originária camponesa, todo ser que tem vida está provido também de um espírito, de um ajaru. Esta é a origem da ritualidade indígena, em que se fazem "pagamentos" e pedidos ao conjunto de seres vivos com os que se interage cotidianamente: a água, as montanhas, as plantas, a terra, os animais, nossos antepassados já falecidos e a nossa família e comunidade humanas.

Outro elemento importante é a busca do equilíbrio, tanto nas relações sociais intrafamiliares e comunais, sanguíneas e espirituais, que implica uma relação com o entorno natural, social e espiritual. Para manter ou eventualmente reestabelecer o equilíbrio entre entornos, é necessário manter um profundo respeito ao outro e os tempos-espaços que requerem para reproduzir sua vida. Este outro são os seres humanos da família, a comunidade e a sociedade em seu conjunto, são também o entorno natural e o espiritual.

As relações de equilíbrio estão baseadas em dar ao outro o que esteja a seu alcance e esperar na mesma medida, por isso as normas comunais de regulação das relações sociais, a inovação contínua de tecnologias para manter estáveis os ciclos de produção agropecuários e as práticas rituais, são a busca de equilíbrios entre todos os seres vivos do planeta e o cosmo.

Finalmente, a complementaridade com todos os seres viventes é outra característica ontológica das ciências endógenas. Sob o princípio de que nenhum ser vivente é completo por si mesmo e que todos necessitamos dos demais: humanos, plantas, animais, terra, água e ancestrais, o 
indígena originário camponês desenvolveu um sistema de complementaridade baseado na reciprocidade, no dom e na redistribuição equitativa.

A complementaridade cotidiana é uma manifestação da cosmovisão baseada na complementaridade do homem que contém algo de mulher e vice-versa, a terra contém a sociedade e vice-versa; e isso pode ser aplicado a todos os elementos naturais, sociais e espirituais da vida: macho-fêmea, seco-úmido, acima-abaixo.

Com isso, considerando estes elementos ontológicos é importante precisar o para que se conhece, o por que se quer conhecer e o que é possível conhecer no marco das ciências endógenas.

A partir de nossa experiência institucional podemos destacar que o objetivo do conhecimento das ciências endógenas (para que se conhece) é para reproduzir a visão de mundo, visão do entorno ou a cosmovisão. O porquê do conhecimento na produção, no filosófico, sobre o ambiente natural e sobre as relações sociais está orientado definitivamente a um feito político: a busca da manutenção ou a restituição da autodeterminação econômica, social e cultural, primeiro da família e em seguida da comunidade. Diante dos movimentos sociais indígenas, agora vemos que a busca da autodeterminação tem também um alcance plurinacional.

A dimensão ontológica de nossas ciências também busca responder à pergunta: o que é possível conhecer? E uma provável resposta das ciências endógenas é que é possível conhecer tudo aquilo que esteja ao alcance dos sentidos. Isto é universal; o que é particular às ciências endógenas é que ela considera a mente, os espíritos, o intuitivo e o subjetivo como parte dos sentidos.

Desta maneira os sonhos, a intuição, as "revelações" de um ancestral falecido que aparece, ou as meditações nas horas de descanso, dias de resguardo, rituais, fazem parte do conhecimento que logo, como todo conhecimento, será utilizado para resolver problemas cotidianos e por isso são considerados conhecimentos científicos endógenos.

Enquanto para a ciência ocidental moderna "tudo é cognoscível", para as ciências endógenas, há um conhecimento que está reservado para pessoas com dons especiais. É o caso dos yatiris andinos, kallawayas ou médicos tradicionais, dos machis mapuche e dos médicos maias, em que o conhecimento médico envolve o estabelecimento de comunicação com plantas e animais, com os espíritos dos ancestrais e outros dons especiais. Não é um conhecimento aprendido, mas sim outorgado por forças energéticas e espirituais que estão em nosso ambiente e por isso, ontologicamente para as ciências endógenas, nem tudo é cognoscível.

As características epistemológicas dos saberes ancestrais consideram o conhecimento como um feito social comunitário ou coletivo e não individual. Por isso se aprende do vizinho, trocam-se 
experiências, crianças e jovens aprendem dos adultos e idosos e vice-versa. Ninguém se considera dono de um conhecimento, seja este de manejo de recursos naturais, de produção, "filosófico" ou outro, porque se sabe que ele foi fruto de uma construção social coletiva. Por isso, temas como as patentes, direitos intelectuais e de propriedade sobre o conhecimento, sempre foram alheios às nações indígenas originárias e se prefere falar de direitos coletivos.

Outro elemento da epistemologia das ciências endógenas é a transmissão do conhecimento assentada em aspectos gerais e não particulares sob a compreensão de que os aspetos particulares irão variar de um ano a outro, de um lugar a outro, isto é, irão variar em tempo e espaço. Por isso não existe uma transmissão linear e repetitiva do conhecimento, mas sim uma transmissão criativa e inovadora.

Este é o elemento que nos permite diferenciar conhecimento ancestral e saberes locais, sendo que o primeiro corresponde aos aspectos gerais e originários tais como a cosmovisão, a caracterização do ambiente natural e social; de maneira que os saberes locais podem ser um conhecimento que, baseado no ancestral, foi inovado de acordo com o contexto social, ambiental e produtivo atual. Considera-se também um saber local aquele que foi adaptado ou inovado a partir de outros contextos culturais ou biofísicos.

Da igual maneira, sob as características sociais e coletivas da construção do conhecimento, sua transmissão criativa e a inovação permanente, todas ambientadas em sua cosmovisão ou visão do ambiente, a relação sujeito-objeto na criação do conhecimento não existe como tal.

Se a cosmovisão indígena originária aponta que a sociedade é parte da natureza e vice-versa, suas relações estão baseadas na complementaridade e o equilíbrio, a sociedade cria e é criada. A relação sujeito-objeto corresponde definitivamente a uma categorização de separação, dualidade e atomização da realidade própria das visões do mundo ocidental eurocêntricas, por isso o objeto de estudo é uma visão forçada a partir de um único ponto de vista.

Por outro lado, e de acordo com o que foi apontado, é possível afirmar que a epistemologia das ciências endógenas estabelece que o conhecimento é fundamentalmente particular e local, e eventualmente universal, ao contrário das ciências ocidentais modernas que afirmam que para que uma ciência possa ser considerada como tal, suas teorias e métodos devem ter um alcance universal de aplicabilidade e replicabilidade.

Por exemplo, uma virtude do conhecimento indígena originário é o profundo e detalhado conhecimento do ambiente natural: tipo de solo, indicador de clima, umidade, que o permitem estabelecer com certa precisão as datas de semeadura, o tipo de espécies e variedade para semear, o 
uso da flora e fauna, a data do ritual. Este conhecimento profundo e detalhado é a base do raciocínio para ter claro que seu conhecimento aplicado a outro contexto cultural e biofísico não necessariamente pode ser aplicado ou replicado, mas é universal porque é parte do universo.

Finalmente, é importante estabelecer que tanto a origem, transmissão, gestão e particularidade do conhecimento indígena originário, se desenvolve em um contexto social e histórico desfavorável e até agressivo contra a ontologia e epistemologia de seu conhecimento. No caso da Bolívia, ainda na última década existe um reconhecimento estatal e da sociedade de que as nações indígenas originárias têm uma cosmovisão própria e particular e um corpo de conhecimentos, diferente da ocidental intencionalmente mestiça boliviana.

Até a presente data (agosto de 2016), se as estruturas estatais segregacionistas e racistas direcionadas às nações indígenas originárias estão sendo desmontadas gradualmente, a percepção de que o indígena é culturalmente inferior, de que sua forma de vida é atrasada e por isso seus conhecimentos e ciências são antigos ou simples "crenças" e práticas, ainda é um sentido comum na sociedade e nas universidades públicas e privadas que vêm de uma ciência eurocêntrica.

O contexto histórico ainda está marcado pelo colonialismo interno em todas as facetas da sociedade, entre elas o da ciência e o conhecimento de origem eurocêntrica. Por isso, é duplamente meritório que as ciências endógenas continuem presentes em vastos espaços territoriais e na vida cotidiana de milhões de pessoas.

O contexto histórico e social explica de alguma maneira que o grau de desenvolvimento das ciências endógenas à primeira vista pareça estático e muitos de seus elementos ontológicos e epistemológicos estejam sofrendo uma deterioração acelerada, restringindo-os a conhecimentos práticos cotidianos e renunciando à possibilidade de construir um meta-conhecimento indígena.

\section{A crise alimentar, a alimentação e a nutrição segundo a ciência ocidental moderna e o desenvolvimento capitalista}

Os diferentes modelos de desenvolvimento e a ciência moderna eurocêntrica como um dos seus importantes instrumentos e conceitos básicos (apresentados em textos e manuais que difundem esta concepção) sem dúvida são causadores da crise da humanidade e, portanto, da crise alimentar.

A princípio, podemos afirmar em que a alimentação é a ação de sustentar ou prover nutrientes necessários aos seres humanos para desenvolver suas atividades biológicas, reprodutivas, 
econômicas e socioculturais durante um ciclo de vida. É a forma e maneira de proporcionar ao organismo os alimentos ou substâncias nutritivas que necessita. A nutrição é o conjunto de atividades que o organismo realiza para transformar e assimilar as substâncias nutritivas contidas nos alimentos: digestão, absorção, utilização e eliminação. A nutrição só pode ser afetada pela alimentação.

É necessário educar a alimentação para influenciar na nutrição e Delgado e Delgado (2014, p.33-34) concluem que:

el concepto de alimentación y nutrición planteado desde la ciencia occidental moderna parte de una visión mecanicista, materialista y antropocéntrica de la vida, con un fuerte énfasis en los aspectos físico biológicos, donde los alimentos son productos con valores nutritivos pero convertidos en mercancías con valor de uso y valor de cambio, que finalmente dependen del mercado internacional dominado por las transnacionales de los alimentos. Según esta visión, los valores nutritivos, solo son: proteínas, hidratos de carbono, grasas, vitaminas, minerales y agua. Estos valores nutritivos están distribuidos de manera desigual en multitud de alimentos que encontramos en la naturaleza. Lo que importa bajo el punto de vista de la nutrición, son los valores nutritivos.

Lamentavelmente, a educação atual e os meios de comunicação estão direcionados a influenciar a sociedade para consumir alimentos que provê o mercado internacional, satisfazendo não apenas os requerimentos mínimos nutricionais dos seres humanos, mas também a ambição das empresas transnacionais da alimentação e seus aliados em todos os países do mundo.

Também é necessário mencionar que a partir da ciência ocidental moderna surgiram nos últimos 50 anos, sérios questionamentos sobre esta visão fragmentada da alimentação. Sobre isso, Aguilar (2011, p.33-34) menciona que:

Ha existido un reduccionismo lógico de pensar la alimentación como un aspecto social mensurable y eminentemente biológico, representado simplemente por el estado de salud óptimo, reducido a su estado nutricional que se constituye como una aproximación útil para fines de control sanitario, pero no para fines de interpretación de los contextos del complejo cultural en los cuales se realiza.

É necessário precisar que a alimentação e a nutrição são conceitos complementares e fundamentais. A necessidade mais básica e primária que toda sociedade deve considerar é a alimentação; portanto, todos os esforços das comunidades ou grupos sociais, incluídos os que constituem as nações indígenas originárias camponesas, está em como organizam a produção, a redistribuição e o consumo de alimentos de sua população. 
A maneira que um grupo social supre suas necessidades está influenciada por dois aspectos: i) físicos, como o entorno natural, o clima ou o tamanho da população; ii) culturais e políticos, como as necessidades simbólicas e culturais, as relações de poder, a divisão do trabalho ou a tecnologia disponível. Por isso, as necessidades alimentares assim como a forma de supri-las, mudam de acordo com o tempo e o espaço, em que a relação da sociedade com a natureza é determinante.

D’Adamo e Whney (1996, p.15), mencionam que:

El grupo sanguíneo es la llave que abre la puerta a los misterios de la salud, la enfermedad, la longevidad, la vitalidad física y la fuerza emocional. Su tipo de sangre determina su susceptibilidad a la enfermedad, los alimentos que usted debería comer y como debería practicar ejercicio. Es un factor clave en sus niveles de energía, en la eficiencia con que usted "quema" las calorías, en su respuesta emocional al estrés y quizá en su personalidad.

Estes importantes avanços a partir de certas comunidades científicas do ocidente moderno, ainda periféricos, são corroborados pelo sábio amauta andino José Ilecas que menciona que esta sabedoria é parte do que os avós nos Andes nos deixaram, com base em uma dieta alimentar registrada a partir dos saberes ancestrais ${ }^{7}$.

Existem outras experiências como as de Juan Carlos Martínez, médico naturista boliviano que pratica a medicina e a saúde com base em dietas vegetarianas de desintoxicação, meditações e ouras práticas de cura e limpeza utilizando o temazcal, a ayahuasca e o São Pedro ${ }^{8}$. As experiências mencionadas corroboram com o fato de que a alimentação é fundamental na saúde humana, mas como parte integral de um todo com a mãe terra, com a natureza, com os astros e com todos os seres vivos da terra.

Sendo assim, apesar de sua transcendência, as condições físico-biológicas não são suficientes para explicar os comportamentos alimentares da sociedade em seu conjunto. Portanto, a comida não é e nunca foi uma mera atividade biológica. A comida é mais que um conjunto de vitaminas, minerais, proteínas e carboidratos escolhidos segundo uma racionalidade estritamente

\footnotetext{
7 "La influencia de la alimentación y los grupos sanguíneos en la salud y la enfermedad del ser humano desde la medicina académica y la medicina tradicional en un escenario intra e intercultural", é o título de um projeto de pesquisa no marco do Programa de Doutorado Diálogo de saberes agroecología y nuevos paradigmas de las ciencias y el desarrollo que está sendo realizado na UMSS, tema proposto por Tatiana Gonzáles.

${ }^{8}$ Ambas são plantas medicinais alucinógenas que foram utilizadas por gerações indígenas para a conexão com o suprahumano, a cura de doenças espirituais e outros, que se utilizam em rituais sagrados com uma preparação prévia e um guia espiritual.
} 
dietética. Tampouco as razões das escolhas alimentares são estritamente econômicas. Comer é um fenômeno social e cultural que implica também o espiritual e simbólico, enquanto a nutrição é um tema fisiológico relacionado à visão ocidental da saúde.

Entretanto, o discurso e práxis nas universidades latino-americanas ainda não superaram o colonialismo interno e externo, especialmente em países em que o neoliberalismo foi melhor executado por governos ditatoriais ou democracias combinadas ao serviço das classes altas, mas que hoje são os setores estudantis e docentes, o suporte das reivindicações nestes países.

Sem dúvidas, a educação é um dos pilares para qualquer processo de mudança que deve ir acompanhada por novos paradigmas da ciência e do desenvolvimento, sendo fundamental revalorizar a sabedoria ancestral sobre a alimentação e a saúde, em que alimento é medicamento e medicamento é alimento.

\section{A alimentação e a nutrição a partir do diálogo intercientífico, a transdisciplinaridade e o "Viver Bem"}

Diante da crise alimentar no mundo, consideramos importante a análise e a reflexão epistemológica do que foram os conceitos dados como válidos pela ciência ocidental moderna sobre o desenvolvimento, a alimentação e a saúde.

Por outro lado, através do diálogo intercientífico, a lei "Marco de la Madre Tierra y el Desarrollo Integral para Vivir Bien" sugerem como um dos seis valores do "Viver Bem" o saber alimentar-se que "é alimentar-se com qualidade e produtos naturais; saber combinar as comidas e bebidas adequadas de acordo com as estações do ano, respeitando os jejuns e ofertando alimentos à Mãe Terra".

Sobre isso, Delgado e Delgado (2014, p.36), apontam que:

Desde los movimientos indígena originario campesinos, de su cosmovisión, identidad y la lógica de la cultura de la vida, se plantea la alimentación como un hecho socio-cultural económico y espiritual donde confluyen y se interrelacionan lo individual con lo comunitario y viceversa. Esto significa que el alimento debe ser accesible para todas las formas de existencia, es decir, no sólo para el ser humano como individuo sino para todas los seres que habitan la Madre Tierra, incluyendo animales, plantas y seres del más allá, donde los alimentos también son parte importante en la relación con los muertos o más bien con los que han pasado a otra vida... [...] En la religiosidad andina, los dioses son criadores, doadores de 
vida; la Pachamama da de comer, tata inti da calor, mama cocha da agua. Entonces cuando se hace referencia a esa relación entre la sociedad, la naturaleza y dios o dioses es a través de los alimentos que dan vida, pero también es a través de los alimentos con los que se contacta con la muerte.

Isto é expressado nas festividades de finados e de todos os santos, quando se recorda e se conecta com os familiares e ancestrais que deixaram este mundo, através dos alimentos que eles mais gostavam, como demonstram Delgado, Tapia e Ricaldi (2012). Portanto, para a cosmovisão andina, o alimento é sagrado e seu manejo e técnicas são sagrados para esta vida e para a outra.

Segundo Huanacuni (2013, p.02),

el alimento es fuente de energía física, mental, emocional y espiritual, por lo tanto, alimento digno es alimento natural y sano, es producto de frutos no producidos sólo para el mercado, sino para la vida, pues emergen desde el afecto, desde la espiritualidad, generando así frutos que tienen ch'ama (fuerza física) y kama (fuerza espiritual), pues desde el acopio de la semilla se cuida que estas sean sanas. Todo el proceso de producción, desde la siembra hasta la cosecha, se basa en el profundo respeto a la vida y a los ciclos naturales de la Madre Tierra y el Padre Cosmos, así como la práctica de los multicultivos rotativos que permiten que el alimento guarde todos los nutrientes de la Madre Tierra.

Delgado e Delgado (2014, p.37) concluem que para os andinos e andinas, o alimento "tiene también una dimensión simbólica, espiritual que sirve de conexión con ámbitos supra humanos y trascendentales. Existe un cariño y conexión con la madre naturaleza al sembrar y cosechar, ya que es una relación de complementariedad y agradecimiento a la tierra proveedora de tanta riqueza". O acesso aos alimentos bons, nutritivos e saudáveis significa riqueza espiritual.

$\mathrm{Na}$ Bolívia, ainda que exista uma tradição e sabedoria das nações indígenas sobre a alimentação e a nutrição, na academia este tema não foi tratado com a devida profundidade, tanto em seus aspectos objetivos como subjetivos, tangíveis e intangíveis, quantitativos e qualitativos, devendo ser analisada multidimensional, transdisciplinar e intercientificamente.

Sem dúvida, pode-se afirmar que a alimentação se constitui antes de tudo como um dos poucos terrenos relevantes e fundamentais para a vida no planeta, portanto, são também suscetíveis de uma quantificação e qualificação precisa e divulgada, mas como uma ação recíproca da natureza e da cultura, que ainda não foi tomada em conta pelas comunidades científicas mais rígidas ou neopositivas da ciência ocidental moderna e que requer uma profunda análise epistemológica.

A partir do diálogo intercientífico, segundo Haverkort, Delgado, Shankar e Millar (2013), parte-se do princípio de que todos os sistemas de conhecimentos no mundo são ciências. Este 
reconhecimento prévio inclui a sabedoria dos povos indígenas originários, com uma própria epistemologia, gnosiologia e ontologia. Considera o processo pelo que necessitam os diferentes desenvolvimentos das ciências dentro de suas próprias dinâmicas e se dedicam à interação e aprendizagem conjunta entre ciências.

O diálogo intercientífico também considera o intercâmbio de métodos e resultados de pesquisas, e a busca de respostas para adaptar seus próprios paradigmas e criar juntos uma pluralidade de ciências, em que a complementaridade possa coexistir com a incomensurabilidade.

Um passo prévio a um diálogo intercientífico, é sem dúvida a construção do diálogo intercultural, que se baseia na revalorização dos saberes locais e a sabedoria ancestral das nações indígenas originárias, em diálogo com a ciência ocidental moderna e outras ciências e culturas. O diálogo e a complementaridade de conhecimentos e ciências são propostos em várias publicações da AGRUCO destacando Delgado e Escobar (2006).

Portanto, o diálogo intercientífico é o encontro e articulação entre as ciências biológicasnaturais e as ciências sociais-humanas com as ciências endógenas como são, por exemplo, o ayurveda na Índia, a medicina chinesa ou a sabedoria kallawaya na Bolívia, apenas para citar algumas ciências ancestrais em ressurgimento.

A partir da ciência ocidental moderna, um avanço muito importante nos últimos 50 anos tem sido o surgimento da pesquisa em perspectiva transdisciplinar que rompe, mas sem desconsiderar, as barreiras disciplinares, buscando uma análise multidimensional (Figura 1) e holística. Existe a partir da ciência ocidental moderna importantes avanços por meio da pesquisa transdisciplinar e a ciência holística que se tomam como caminhos importantes para o diálogo intercientífico. 


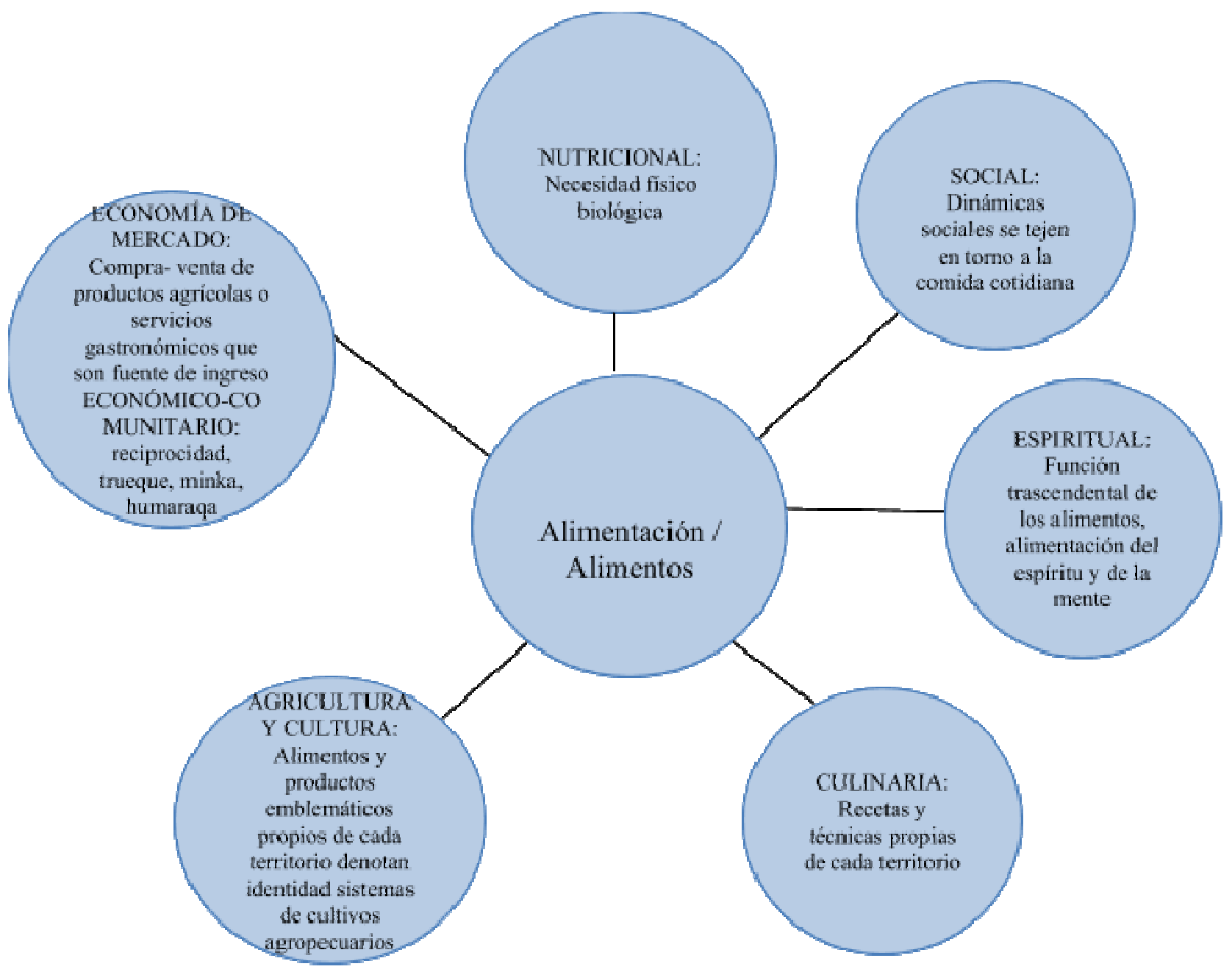

Figura 1. Perspectiva multidimensional y transdisciplinar de la alimentación

Fonte: Delgado y Delgado (2014).

A alimentação a partir da perspectiva multidimensional e transdisciplinar implica considerar as seguintes dimensões: social, econômica, cultural e política. Além disso, implica a consideração da visão das nações indígenas originárias camponesas, em que se destaca o espiritual e o simbólico dos alimentos que se manifesta na energia vital ou ispalla (em aymara) que não é o mesmo que energia calórica. A ispalla é a essência ou o ajayu (em aymara) dos alimentos manifestada no carinho transmitido em todo o processo produtivo, em sua transformação (se fosse o caso) e na elaboração das refeições. Delgado (2002) menciona que segundo testemunhos de camponeses de 
Tapacarí, seria o deus da semente ${ }^{9}$.

Outro conceito importante para o diálogo intercientífico é o paradigma qualitativo, que aplicado à alimentação, representa um enfoque científico que abarca as visões do mundo através de teorias e métodos de pesquisa baseados no uso da história oral, as histórias de vida, a análise do discurso, a observação participante e as percepções das comunidades envolvidas. Portanto, o uso de métodos qualitativos para determinar o valor dos alimentos, rompe com o critério de valorização das determinações quantitativas do valor nutricional como única forma de caracterização, buscando, assim, sua complementaridade.

O conceito e análise da alimentação a partir do diálogo intercientífico, considerando a pesquisa transdisciplinar e os métodos qualitativo e quantitativo, devem permitir planejar pesquisas científicas endógenas que permitam o diálogo com a pesquisa científica ocidental moderna.

Sobre isto, Haverkort, Delgado, Shankar e Millar (2013, p.18), mencionam que a pesquisa endógena é:

la investigación llevada a cabo por las comunidades de conocimiento indígenas y locales que utilizan las formas indígenas de aprendizaje, los métodos transdisciplinarios y el aprendizaje de cooperación con otras ciencias, con el objetivo de desarrollar las ciencias endógenas con apoyo de una comunidad que se basa en el diálogo intercientífico. Por tanto esta investigación es eminentemente participativa y revalorizadora de los saberes locales, ancestrales y la sabiduría de las naciones indígenas originarias campesinas.

O diálogo de saberes é a premissa fundamental do diálogo intercientífico que implica buscar ligações e a inter-relação entre os conhecimentos sobre a alimentação desenvolvidos a partir da ciência ocidental moderna, com os saberes ancestrais e a sabedoria das nações indígenas originárias camponesas. A partir do diálogo de saberes e o diálogo intercientífico, propõe-se reconstruir uma concepção e visão alternativa da alimentação sob a perspectiva de planejar um sistema alimentar baseado nos sistemas tradicionais das nações indígenas originárias camponesas e o sistema alimentar agroecológico.

Seguindo esta perspectiva, como estratégia de produção e reprodução da vida social, a alimentação constitui um complexo sistema em que interagem uma ampla gama de fatores como sua projeção histórica da vida social e que ao mesmo tempo é uma projeção de sua fisiologia. Isto significa que de nenhum modo se constitui como um fenômeno estático ou isolado, sua dinâmica é

\footnotetext{
${ }^{9}$ Sobre este tema, no almanaque de AGRUCO do ano de 1999 trabalha-se com testemunhos camponeses, a concepção andina da alimentação e da biodiversidade (ver site: ww.agruco.org).
} 
de constante consumo-produção e reprodução de significações, de percepções e de saberes, fenômeno que o converte em um espaço e tempo dignos de interpretar-se com totalidade.

O comportamento alimentar tem desde tempos ancestrais múltiplos determinantes. Os seres humanos têm a necessidade de aprender boas escolhas alimentares não por um método de causa e efeito, mas a partir de um saber coletivo que se constituiu ao longo das gerações, sob a forma de um corpo de crenças, algumas confirmadas pela experiência, outras completamente simbólicas ou mágicas, como o jejum, a busca do sagrado ou as cosmovisões ao que denominaram pautas de alimentação herdadas.

Estas pautas de alimentação herdadas são, por sua vez, cruciais para a reprodução das sociedades, como também para manter o equilíbrio e a relação de complementaridade entre os humanos com a natureza e os espíritos.

As nações indígenas originárias camponesas herdaram a essência desta sabedoria para acessar alimentos que permitam uma vida saudável e sustentável na comunidade, o que implica em não ser uma ação exclusivamente individual, mas coletiva. E ao se falar de coletividade, uma ou várias nações se expressam no Estado, que no caso de Bolívia se constitui em um Estado Plurinacional, onde se reconhece na Constituição Política do Estado (CPE) pela primeira vez o comunitário.

Sem dúvida, esta identidade está intimamente relacionada com a terra e o território, que são temas fundamentais em todos os congressos e cúpulas das organizações matrizes das nações indígenas do oriente e ocidente da Bolívia. O território está intimamente relacionado à identidade, mas fundamentalmente à pachamama, que é a expressão mais clara de sacralizar o espaço, a terra, o território por meio da oferenda de agradecimento ou pagamento que faz com a ch'alla que é dar-lhe uma bebida ou uma comida à mãe terra, ou uma mesa ritual com diferentes componentes ou mesmo alimentos.

Nas nações indígenas originárias, essa relação ainda considera a natureza como um ser sagrado e doador de vida, que é conhecida e se expressa como pachamama ou Mãe Terra. Portanto, o ser humano, como os outros seres vivos são partes da Mãe Terra a que veneram e respeitam. Um tempo espaço importante é no carnaval ou el anata (em aymara), quando são feitas oferendas pelos alimentos recebidos durante a colheita. Outro tempo espaço importante é o mês de agosto (mês da Pachamama), em que se observa o cosmos, as nuvens, os astros, as plantas, os animais e seu comportamento para prever o clima para a produção agrícola.

A produção de alimentos nas cosmovisões indígenas originárias e camponesas se distingue 
de qualquer outra pela base biológica de seus processos de produção, isto é, que depende dos ciclos naturais do calendário agrícola e das circunstâncias meteorológicas e climáticas com as quais é preciso dialogar permanentemente. As diferentes nações e culturas indígenas originárias no mundo e em especial a cultura andina, desenvolveram diversas formas de diálogo com a natureza e com os ancestrais, chegando a uma complementaridade com os ciclos naturais para suprir as necessidades de alimentação, aplicando seu trabalho ao cultivo de plantas e à criação de animais. Ao longo da história, se produz assim um processo de co-evolução entre a natureza ou hamama Mãe Terra (para os andinos) e a sociedade.

Esta diversidade cultural andina se plasma em suas preparações culinárias, em que cada família, comunidade, município, representa uma gama de sabores e receitas que marcam o caráter da comida boliviana e, portanto, de sua identidade. É através das refeições que se integra o individual com o comunitário (SOLER, 2004).

Por meio da herança cultural se transmite de geração em geração, um conjunto de saberes e habilidades práticas que permitem identificar os alimentos comestíveis mediante a aquisição de preferências e aversões fundadas na experiência, mas que estão muito relacionadas à saúde e ao bem-estar não apenas físico, mas social e espiritual.

Cada cultura gera uma culinária, entendida como a arte de cozinhar (ingredientes, aromas, técnicas de preparação e maneiras de servir e comer), com classificações particulares e regras precisas, tanto em relação à preparação e combinação de alimentos, como relativas à sua coleta, produção conservação e consumo, sempre adaptada ao contexto.

Como afirmam Marsden e Little (1990), citado em Soler (2004, p2),

A la hora de estudiar, como cubrimos nuestras necesidades de alimentación en la actualidad, no se puede acudir a un sector aisladamente, como la agricultura o la industria de transformación alimentaria. Por otra parte, tampoco puede comprenderse de forma aislada el funcionamiento de un sector, por ejemplo la agricultura indígena campesino o la agroindustria, sin tener en consideración sus interrelaciones dentro de una organización económica y social, más amplia que es el sistema agroalimentario.

Por isso, no processo de socialização, adquirimos de um modo mais ou menos inconsciente, certas normas básicas para atuar no meio social onde se produz uma aprendizagem social relativa às regras culinárias e de alimentação que fazem parte dos conhecimentos e habilidades transmitidos e adquiridos e que se interiorizam de forma similar. 


\section{A sustentabilidade alimentar como premissa para as políticas de Segurança e Soberania}

\section{Alimentar}

A sustentabilidade alimentar é um conceito que aparece como uma proposta da academia como sendo coadjuvante para a operacionalização da segurança e soberania alimentar. Neste caso, se considera para a elaboração dos indicadores dos direitos à alimentação, mas principalmente os indicadores de segurança alimentar. Além disso, esse conceito pode guiar na Bolívia a implementação da Constituição Política de Estado (CPE) e as leis relacionadas a estes temas.

Geralmente, as transformações ocorrem pela ação direta da população, influenciada por seus costumes, cultura, economia e cosmovisão, mas também se pode dar pela influência das políticas públicas que os Estados planejam através da Constituição Política de Estado (CPE), leis e decretos que são operacionalizados em programas e projetos e, geralmente são impulsionados através do órgão executivo em nível nacional, departamental (ou estadual) e municipal. As transformações também sofrem influência das políticas e do poder econômico internacional, no qual o sistema capitalista impera e domina.

No caso da Bolívia, está claro que as políticas públicas até 2005 tem sido favoráveis para a segurança alimentar, porém com menos suporte à soberania alimentar. Esta assertiva se deve devido os processos de investigação, inovação e transferência de tecnologias agropecuárias que vem seguindo os modelos da Revolução Verde e da engenharia genética. As mudanças de cunho tecnológico deveriam considerar as tecnologias ancestrais e locais e, não apenas priorizar tecnologias modernas que tem como premissa - apenas o lucro - que, geralmente, não favorecem as grandes populações pobres e famintas, cujas necessidades deveriam ser direcionadas à este público.

As novas políticas públicas na Bolívia, os novos conceitos, enfoques de desenvolvimento e novas tecnologias vão no sentido do cuidado da vida em harmonia com a Mãe Terra. Então, o Estado Plurinacional precisa gerar uma estrutura consonante com a dinâmica da comunidade, isto é, com o conceito de que tudo tem vida, com o consenso, a complementaridade e o equilíbrio.

Desde os anos 80 surgem instituições de investigação e desenvolvimento como a AGRUCO na Bolívia e PRATEC no Peru, que planejam alternativas ao sistema alimentar convencional, baseado principalmente na revalorização dos conhecimentos ancestrais e saberes locais das comunidades andinas e na agroecologia como uma disciplina científica da modernidade, existindo 
várias publicações e uma metodologia de revalorização. Além disso, estas instituições também possuem dados com mais de 1.000 registros dos diferentes saberes e conhecimentos de modo a valorizá-los.

\section{A CPE e as leis relacionadas à Segurança e Soberania Alimentar}

Estes processos isolados e marginalizados das experiências de diálogos de saberes e diálogo intercientífico nas políticas públicas dos governos neoliberais começam a ser acolhidos na Bolívia desde 2005 com o Governo do primeiro presidente indígena Evo Morales Ayma e que de alguma maneira fui introduzido na nova Constituição Política de Estado promulgada em janeiro do ano de 2009 e na lei "Marco da Mãe Terra e Desenvolvimento Integral para "Viver Bem”" promulgada em outubro de 2012.

Uma proposta que ganhou destaque nos últimos anos nas políticas sobre a segurança e soberania alimentar tem por base de que os alimentos e a agricultura precisam ficar de fora dos acordos comerciais e internacionais, sobretudo, para evitar que estes sejam mercantilizados por grandes corporações transnacionais e multinacionais ou pelos Estados envolvidos nos ditos tratados.

É importante fortalecer o acesso aos mercados locais sem desestruturar os circuitos de intercâmbio de produtos alimentícios que existe em nível local, com preços justos que cubram os custos reais de produção, para que os povos originários (indígenas) e camponeses, trabalhadores e trabalhadoras e setores populares da população boliviana, possam alcançar o bem viver, sendo a economia comunitária uma oportunidade para encontrar alternativas a economia de mercado, que hoje são reconhecidas na CEP junto com a economia estatal e social cooperativa, como o modelo econômico do país, denominada economia plural.

Uma das premissas desta proposta é que os alimentos constituem um direito humano, além disso, estes precisam ser saudáveis, nutritivos e com identidade cultural. Neste sentido, as leis precisariam influenciar e estimular na produção local e ecológica para evitar a dependência e a utilização de energia não renovável (transporte de alimentos por longas distâncias) que afeta, sobremaneira, a conservação e o respeito à Mãe Terra.

Por outro lado, a Bolívia ratificou por lei, os direitos humanos dos povos originários e foi aprovado na Organização das Nações Unidades (ONU) em 13 de setembro de 2007. Um direito fundamental dos povos originários é produzir seu próprio alimento. Para isto, é preciso ter acesso à terra, acesso aos recursos naturais, condições de manejo, bem como de armazenar suas próprias sementes, que é a herança comum dos povos e está a serviço da humanidade. Deste modo, há que se 
enfrentar as empresas multinacionais e transnacionais que se dedicam a lucrar usurpando práticas e saberes locais e conhecimentos ancestrais.

O grande problema da humanidade não é a falta de alimentos, mas sim que existe uma má distribuição que está condicionada pelas políticas e/ou acordos internacionais nos quais os Estados, por estarem alinhados ao modelo capitalista globalizador, deixam de lado pequenos produtores e produtoras (indígenas camponeses), que por sua vez, através do tempo tem sido os provedores e provedoras de alimentos para a grande maioria da população rural e urbana.

O contexto e as políticas públicas do governo atual são sumariamente importantes para dirigir e facilitar recursos para o setor produtivo. Também é de fundamental importância que o Estado promova a inovação tecnológica para a produção de cultivos estratégicos nas regiões mais vulneráveis do país.

O atual governo está implementando políticas públicas, nas quais se planejam ações que permitam uma maior participação dos diferentes atores que estão imersos no processo de produção de alimentos. Concretamente, se busca a interação entre os representantes ou instituições do governo com pesquisadores e pesquisadoras da academia, pequenos produtores e produtoras indígenas (camponeses) e outros setores, para que se possa dar materialidade à Soberania Alimentar (SOBAL) e à Segurança Alimentar e Nutricional (SAN) na Bolívia.

Surgem também, pressões e negociações, principalmente do setor empresarial e agroindustrial que direcionam suas estratégias para fortalecer o sistema - alimentar agroindustrial ao qual pertencem, mas totalmente direcionado ao mercado internacional e seguindo o modelo neoliberal, promovendo assim, leis contraditórias com o enfoque da SOBAL e SAN, muitas vezes violando a CPE e descumprindo as leis que prezam por estes valores.

Em janeiro de 2009, o governo atual aprovou na CPE, a menção explícita da segurança e soberania alimentar que apresenta no seu artigo 16 inciso II - dos direitos fundamentais - o seguinte: "El Estado tiene la obligación de garantizar la seguridad alimentaria, a través de una alimentación sana, adecuada y suficiente para toda la población".

No seu Título VIII, o capítulo primeiro sobre relações internacionais a CPE explicita o seguinte: "Seguridad y soberanía alimentaria para toda la población; prohibición de importación, producción y comercialización de organismos genéticamente modificados y elementos tóxicos que dañen la salud y el medio ambiente".

No seu Artigo 407 (da CPE) se menciona no inciso 13 que: "Son objetivos de la política de desarrollo rural integral del Estado, en coordinación con las entidades territoriales autónomas y 
descentralizadas: 1) Garantizar la soberanía y seguridad alimentaria, priorizando la producción y el consumo de alimentos de origen agropecuario producidos en el territorio boliviano".

Nos artigos 300 e 302 se faz menção explícita sobre as competências e as autonomias departamentais e municipais a: "Proyectos de fuentes alternativas y renovables de energía preservando la seguridad alimentaria...”. Sem dúvida, a importância da revalorização dos saberes ancestrais e locais das nações indígenas originárias camponesas são a base da segurança e a soberania alimentar.

$\mathrm{Na}$ CPE surge a primeira contradição onde um dos objetivos da política de desenvolvimento rural integral do Estado é: "Garantizar la soberanía y seguridad alimentaria, priorizando la producción y el consumo de alimentos de origen agropecuario producidos en el territorio boliviano (art. 407)". No artigo 409 está explícito: "La producción, importación y comercialización de transgénicos (OGM) será regulada por ley".

No artigo 255, inciso 8, referindo às relações internacionais, sobre a negociação, a assinatura e ratificação dos tratados se menciona como um dos princípios o seguinte: "Seguridad y soberanía alimentaria para toda la población; prohibición de importación, producción y comercialización de organismos genéticamente modificados y elementos tóxicos que dañen la salud y el medio ambiente."

A partir da CPE tem sido criadas e implementadas uma série de leis e normas para melhorar o acesso à disponibilidade dos alimentos com soberania para a população boliviana em geral, porém, estas leis apresentam sérias contradições. De fato, existe uma diversidade de leis e normas que estão direcionadas a enfrentar a crise alimentar e reduzir os altos índices de pobreza e desnutrição.

A lei de regulação e promoção da produção agropecuária - de reflorestamento ecológico (lei 3.525) e a lei de revolução produtiva agropecuária comunitária (lei 144), apresentam maior contradição em relação aos transgênicos ou OGM (organismos geneticamente modificados) e a produção de alimentos agroindustriais (com utilização intensa de insumos externos, principalmente agroquímicos).

No artigo 15, inciso 2, se diz: "No se introducirán en el país paquetes tecnológicos agrícolas que involucren semillas genéticamente modificadas de especies de las que Bolivia es centro de origen o biodiversidad, y que atenten contra el patrimonio genético, la biodiversidad, la salud de los sistemas de vida y la salud humana." No artigo 19, inciso 5 se menciona que: "se establecerán disposiciones para el control de la producción, importación y comercialización de productos 
genéticamente modificados".

A lei dos direitos da Mãe Terra (071) e a lei marco da Madre Terra e o desenvolvimento integral para o "Viver Bem" (300), tem uma visão e perspectiva muito relacionada à sustentabilidade da vida e alternativa ao desenvolvimento capitalista.

A lei 300, art. 5, inciso 2 é do nosso ponto de vista uma base fundamental para a construção de novos paradigmas das ciências e o desenvolvimento alternativo, pois considera o vivir bem como:

[...] el horizonte civilizatorio y cultural alternativo al capitalismo y a la modernidad que nace en las cosmovisiones de las naciones y pueblos indígena originario campesinos, y las comunidades interculturales y afrobolivianas, y es concebido en el contexto de la interculturalidad. Se alcanza de forma colectiva, complementaria y solidaria integrando en su realización práctica, entre otras dimensiones, las sociales, las culturales, las políticas, las económicas, las ecológicas, y las afectivas, para permitir el encuentro armonioso entre el conjunto de seres, componentes y recursos de la Madre Tierra. Significa vivir en complementariedad, en armonía y equilibrio con la Madre Tierra y las sociedades, en equidad y solidaridad y eliminando las desigualdades y los mecanismos de dominación. Es vivir bien entre nosotros, vivir bien con lo que nos rodea y vivir bien consigo mismo.

Esta mesma lei, também considera o diálogo de saberes como um princípio que permite um reconhecimento dos saberes ancestrais como ciências endógenas, dando lugar ao diálogo intercientífico. Planeja o desenvolvimento, denominado na lei como desenvolvimento integral como:

el proceso continuo de generación e implementación de medidas y acciones sociales, comunitarias, ciudadanas y de gestión pública para la creación, provisión y fortalecimiento de condiciones, capacidades y medios materiales, sociales y espirituales, en el marco de prácticas y de acciones culturalmente adecuadas y apropiadas, que promuevan relaciones solidarias, de apoyo y cooperación mutua, de complementariedad y de fortalecimiento de vínculos edificantes comunitarios y colectivos para alcanzar el vivir bien en armonía con la Madre Tierra. No es un fin, sino una fase intermedia para alcanzar el vivir bien como un nuevo horizonte civilizatorio y cultural.

Estes avanços e contradições na CPE, estas e outras leis como a lei das Organizações Econômicas Campesinas, Indígenas Originárias (OECAS) e de Organizações Econômicas Comunitárias (OECOM) para a integração da agricultura familiar sustentável e a SOBAL (Lei 338), necessitam serem implementadas de maneira mais intensa, para que possa superar as contradições e 
conquistar a SOBAL e a SAN, já que ainda existe um longo caminho a percorrer, sobretudo pela ausência dos decretos que as regulamentem, bem como orçamentos para igualmente superar as contradições entre a visão extrativista e capitalista que contrapõem a sustentabilidade da vida.

\section{“Plano de Desenvolvimento Económico e Social 2016 -2020 (PDES 2016-2020) de Bolivia” e o diálogo intercientífico para a sustentabilidade e a soberania alimentar}

De acordo com o "Plano de Desenvolvimento Económico e Social" (2016, p.12), e o Plano Nacional de Desenvolvimento (NDP, 2006-2011), entre as principais realizações da Bolívia soberana que repercutiriam no cenário internacional e no âmbito das Nações Unidas, tem-se os seguintes reconhecimentos:

- A existência de diferentes abordagens, visões e ferramentas para atingir o desenvolvimento sustentável.

- $\quad$ O reconhecimento por parte de alguns países dos direitos da Mãe Terra.

- O reconhecimento de "Viver Bem" em harmonia com a Mãe Terra como um enfoque universal e eventos para a discussão internacional.

- $\quad \mathrm{O}$ reconhecimento de diálogo intercientífico entre os saberes ancestrais e as ciências modernas e a constituição de um mecanismo participativo para facilitar o diálogo.

- $\quad$ O reconhecimento de uma abordagem alternativa para a economia verde e o pagamento por serviços ecossistêmicos no marco do "Viver Bem", que é a gestão dos sistemas de vida.

- $\quad$ O reconhecimento de uma abordagem alternativa para pagamento pelos serviços prestados no campo da redução de desmatamento e degradação florestal (REDD +) com uma abordagem conjunta para a mitigação e adaptação para o manejo integral e sustentável das florestas.

- $\quad$ O direito humano à água e ao saneamento básico.

- Direitos dos Povos Originários (Indígenas)

- A disseminação de alimentos tradicionais, como a coca e quinoa.

Consideramos, portanto, que a Bolívia soberana e seus reconhecimentos internacionais, permitem incidir principalmente sobre o planejamento de novos paradigmas das ciências e o desenvolvimento, como alternativas para o desenvolvimento capitalista, que envolve a abertura do diálogo intercultural e de saberes para o diálogo intercientífico.

É importante fazer referência, ao "Plano de Desenvolvimento Económico e Social 2016 2020" (PDES 2016-2020), destacando alguns aspectos que se referem ao diálogo intercientífico, o desenvolvimento sustentável e a segurança e soberania alimentar. No PDES (2016, p. 59, 63 e 64), 
no pilar 1, a erradicação da pobreza extrema surge, pela primeira vez, portando uma visão mais abrangente da pobreza, considerando três dimensões: a material, a pobreza social e a espiritual.

Se faz este destaque por considerarmos uma inovação nas políticas públicas em todo o mundo, a consideração que se passa a fazer para as dimensões sociais e espirituais, levando em conta o conhecimento ancestral e sabedoria das nações de camponeses indígenas e dando alguns exemplos. Entre as metas para combater a pobreza social se planejam alcançar os seguintes resultados:

1) "Se ha recuperado, fortalecido e incrementado la práctica de al menos 6 valores compartidos y prácticas comunitarias: ayni, mink`a, tama, thumpa, arete guasu y apthapi, en organizaciones barriales, comunitarias, instituciones públicas, privadas, municipios y organizaciones sociales".

2) "Se ha fortalecido la práctica y promoción de las múltiples expresiones culturales que constituyen el patrimonio material e inmaterial del Estado Plurinacional (arte, textil, pinturas, danzas, música, vestimenta, pensamiento, oralidad, memoria y otras)".

Uma ação fundamental para a conquista dos resultados é: "Profundizar la transformación curricular del sistema educativo plurinacional (SEP), incorporando los saberes, conocimientos y tecnologías de las naciones y pueblos indígena originario campesinos en los planes y programas curriculares diversificados y regionalizados”. Acreditamos que essas ações também devem ser direcionadas ao sistema universitário boliviano a partir de experiências como as desenvolvidas e expressas pelos autores dos artigos nesta publicação.

No PDES (2016, p. 93), no seu Pilar 3, a saúde, educação e esporte no modelo educacional social e comunitário da comunidade é proposto como uma das ações fundamentais: "Recuperar, desarrollar y revalorizar el conocimiento sobre la lengua, cultura, saberes y conocimientos de cada nación y pueblo indígena originario campesino, mediante la consolidación de una educación intra intercultural y plurilingüe".

No Pilar 4, (2016, p. 95 - 96) que versa sobre a soberania científica e tecnológica, afirma-se que a Bolívia tem a capacidade de desenvolver o conhecimento e a tecnologia em áreas estratégicas, produtivas e de serviços, complementando os saberes e as experiências tradicionais locais com o conhecimento da ciência moderna mediante o diálogo intercientifico. $\mathrm{O}$ desenvolvimento do próprio conhecimento e tecnologia é fundamental para o cumprimento do Plano e alcançar os diferentes resultados, já que estes influenciam a prestação de serviços básicos, impulsionando processos de comunicação, educação, empresas produtivas, iniciativas de energias alternativas e transformação de matérias-primas para a produção de alimentos. Em última análise, superar a dependência 
científica e tecnológica é fundamental para impulsionar uma economia plural, mudar a matriz energética e o padrão de exportação primária.

No pilar 8 do PDES 2016 -2020 (2016, p. 143 - 144), para a Soberania Alimentar estão previstas metas importantes no que diz respeito à produção de alimentos como por exemplo a soberania através da produção local de alimentos, cujo enfoque é o reconhecimento, bem como a promoção da diversificação da produção, proteção das variedades locais e a promoção da cultura e das tradições alimentares. Para isso tem-se considerado várias ações, tais como: "Diversificar la agricultura familiar y comunitaria, con protección de las variedades locales y promover la agricultura ecológica y orgánica.”

No pilar 9, a soberania ambiental com desenvolvimento integral e a meta para o desenvolvimento de sistemas produtivos sustentáveis no marco de processos de gestão territorial se destaca o seguinte resultado: "Se han fortalecido los sistemas productivos ambientalmente amigables y con prácticas sustentables, priorizando la producción ecológica y orgánica”. Uma ação específica fundamental é: "Fortalecer la seguridad y soberanía alimentaria a través de la conservación, uso y aprovechamiento integral y sustentable de los componentes de la biodiversidad con enfoque de gestión territorial".

Uma conclusão preliminar deste processo de desenvolvimento e implementação de leis, é que um marco normativo suficiente na Bolívia, em que pese algumas contradições, o que ainda é muito incipiente é a sua implementação e monitoramento para medir o impacto - daquelas que se efetivaram -, que tem como objetivo alcançar a soberania, segurança e sustentabilidade alimentar.

\section{Do diálogo de saberes e a transdisciplinaridade ao diálogo intercientífico para a sustentabilidade alimentar}

Depois de 30 anos de vida institucional (da AGRUCO) pode-se dizer que, o diálogo de saberes, que parte da valorização da sabedoria das nações indígenas e camponesas no mundo (o que tem sido chamado de intraculturalidade) e transdisciplinaridade (mais no meio acadêmico) têm sido a base para a sustentação conceitual e metodológica de um quadro teórico para contribuir na construção de novos paradigmas da ciência e desenvolvimento tal como consagrado no diálogo intercientífico.

Os diálogos ocorrem no cenário das nossas experiências, um fator-chave nos processos de 
aprendizagem é que estes são baseados no reconhecimento pleno de todos os interlocutores, dos seus valores e princípios, conhecimentos, tecnologias e crenças, estratégias que fazem parte das suas vidas diárias e suas inserções na comunidade tais quais: um ayllu e uma marka, um território comunitário de origem, uma capitania ou uma tenta, aspectos que os identificam como membros de uma nação ou um grupo cultural, que no caso da Bolívia são reconhecidos como parte do Estado Plurinacional, constituem este cenário. Alguns desses diálogos são iniciados por cientistas comprometidos com os processos de mudança que ocorrem no mundo na busca de alternativas ao capitalismo selvagem e predatório da vida.

Como centro universitário temos formado comunidades de aprendizagem em que o diálogo entre os saberes locais, a sabedoria dos nossos ancestrais, juntamente com os conhecimentos científicos ocidentais e eurocêntricos modernos, tem nos fornecido - e devem dar suporte - para fazer e recriar conhecimentos ou gerar novos conhecimentos para proporcionar uma melhor qualidade de vida, ou melhor, para "Viver Bem" (como diríamos, desde a visão das nações indígenas originárias e camponesas).

Em nosso papel como parte da universidade pública, o diálogo pode permanentemente e continuamente recriar novos programas de formação, articulada a uma pesquisa participativa e valorizadora e aplicadas em programas de "desenvolvimento endógeno sustentável" como uma interface para "Viver Bem". O programa de formação continuada com uma abordagem intercultural e descolonizadora e o programa "Desarrollo: Estrategias de Vida en Comunidades de Bolivia y Latinoamérica", apontam para a necessidade de fortalecer as nações indígenas originárias e camponesas, que vem ao longo dos anos sendo negligenciados, sobretudo no ensino superior.

A partir da experiência e do desenvolvimento institucional da AGRUCO podemos resumir o processo de diálogo em duas fases: a intraculturalidade e a interculturalidade, que academicamente vem sendo concretizadas na transdisciplinaridade, cujos conceitos serão desenvolvidos a seguir:

- $\quad$ O diálogo intracultural que é a valorização da sabedoria ancestral e dos saberes e tecnologias locais em comunidades quechuas, aymaras, principalmente das províncias do sudoeste de Cochabamba. É necessário ressaltar que a província Tapacarí, cujas características socioeconômicas, culturais e de ecossistemas têm permitido desenvolver por mais de dez anos, pesquisas participativas que impulsionam a valorização destes saberes e práticas. Como resultados foram defendidas um número significativo de teses de estudantes de graduação e pós-graduação que contribuíram para implementar projetos piloto com o enfoque para o desenvolvimento sustentável. Esta valorização é possível se houver uma "oferta" para o intercâmbio de conhecimentos. Neste 
sentido, a abordagem nas práticas agroecológicas, cuja origem vem de um contexto europeu, foi adaptada aos nossos contextos e resultou em vários trabalhos.

- $\quad$ O diálogo intercultural se refere às relações complexas, negociações e trocas culturais, que buscam desenvolver uma interação entre as pessoas, conhecimentos e práticas culturalmente diferentes; uma interação que reconhece e que parte das desigualdades sociais, econômicas, políticas e de poder e das condições institucionais que limitam a possibilidade de que o "outro" pode ser considerado como um sujeito com identidade, diferença e agência a capacidade de agir (WALSH, 2005, p. 10).

- $\quad \mathrm{O}$ diálogo intercultural se refere principalmente às atitudes e às relações sociais de um povo ou cultura, com referência as outras pessoas ou culturas, ou as suas características e produtos culturais. É a troca de conhecimento e de diálogo, em que o conhecimento científico ocidental moderno representa apenas mais um.

No entendimento de que os sistemas de conhecimento são inerentes às matrizes culturais, sendo a ciência ocidental moderna inerente à cultura de origem eurocêntrica, é o diálogo de saberes e a busca de pontes epistemológicas com as ciências endógenas ou as ciências da China, Índia, Andina, Mesoamericanas, Africanas, Maoris da Nova Zelândia, aquelas que têm permitido através de redes (entre Ásia, África, Europa e América Latina) construir e fortalecer a sabedoria ancestral e os saberes locais para o "Viver Bem" como alternativa ao desenvolvimento capitalista.

A interação constante com as organizações matrizes em nível nacional, regional e provincial do Conselho Nacional de Ayllus e Markas de Qullasuyu (CONAMQ), da Confederación Indígena del Oriente, Chaco y Amazonía Boliviano (CIDOB), da Confederación Sindical Única de Trabajadores Campesinos de Bolivia (CSUTCB) e da Confederación Nacional de Mujeres Campesinas Indígenas Originarias de Bolivia "Bartolina Sisa" (CNMCIOB-BS) têm sido fundamentais para consolidar projetos educacionais, por exemplo, destaca-se neste processo (como um continuum) o papel que desempenharam na constituição do Programa de Formación Continua Intercultural Descolonizador (PFCID).

Em nível da América Latina, o trabalho em conjunto das organizações indígenas com ONGs como Oxlajup Ajpob (Guatemala), Kumefelem (Chile), Pasos del Jaguar (El Salvador), CEPROSI (Peru) e Surcos Comunitários (Colômbia) vem conquistando resultados interessantes nas experiências com processos de educação intra e intercultural. Transdisciplinaridade, concebida como um processo integrador de pesquisa e formação acadêmica tem a perspectiva de contribuir para a sustentabilidade alimentar e o desenvolvimento sustentável, mas também prezando por uma 
abordagem integral que incorpore entre os atores envolvidos na pesquisa- desenvolvimento, e não apenas acadêmicos ou comunidades científicas de diferentes disciplinas, mas também aos investigadores locais (indígenas, camponeses, etc.). A transdisciplinaridade é um enfoque que surge principalmente na Europa e atualmente se constitui como uma das mais importantes contribuições da ciência, ao "desenvolvimento" e a análise de novos paradigmas da ciência.

Rist e Delgado (2009) definem a transdisciplinaridade como uma etapa superior da interdisciplinaridade e pode ser entendida como um processo de autoformação e pesquisa-ação que se orienta sobre a real complexidade de cada contexto, excedendo os limites do conhecimento disciplinar, de modo que a pesquisa e a recriação de alternativas e soluções são definidas independentemente do seu conhecimento específico e metodológico.

A transdisciplinaridade, portanto, assume a prioridade de transcender as disciplinas e a simples interação mecânica ou uma somatória de disciplinas, cada uma com suas teorias, métodos e metodologias (multidisciplinaridade e interdisciplinaridade). Neste nível, os limites desaparecem diante das várias disciplinas e se constituem em um sistema total que sobressai o plano das relações e interações entre tais disciplinas, dando origem a uma macrodisciplina, mas, principalmente, dá abertura a outras formas de conhecimento e a outras culturas, o que temos denominado diálogo intercultural e intercientífico, no qual se reconhece a cada cultura e a cada conhecimento como parte de um todo que interage (RIST; DELGADO, 2009).

As experiências transdisciplinares na AGRUCO tem ocorrido permanentemente, especialmente por meio de processos de formação coletiva. Este é o caso dos cursos de nível técnico, onde os professores (acadêmicos e locais) entram em diálogo aberto com os estudantes (repositórios dos sistemas de sabores locais ancestrais). Por formalidades, os professores dirigem os exercícios cognitivos, na prática, é uma aprendizagem comunitária, já que "todos aprendem e todos ensinam" dentro de um contexto acadêmico, onde também participam como "professores" sábios das nações indígenas originárias.

O diálogo intercientífico pode ser entendido a partir de duas perspectivas. Primeiro, o diálogo pode demarcar no âmbito da relação de duas ou mais ciências, cuja raiz está dentro do mesmo paradigma e matriz civilizatória, isto é, compartilhar dos mesmos princípios ontológicos, gnoseológicos e epistemológicos (diálogo intercivilizatório); Segundo, o diálogo intercientífico pode ser materializado no relacionamento de dois ou mais sistemas de conhecimento científico, cuja matriz civilizatória seja diferente, de modo que os princípios ontológicos, gnoseológicos e epistemológicas são diferentes, mas podem ser complementares, com base em um processo 
revalorizador e reconhecendo que ambos os sistemas possuem a mesma importância, validade e relevância (DELGADO, 2006).

O diálogo intercientífico pode ser definido ainda, como sendo um processo de complementaridade entre saberes teóricos, métodos aplicativos e de pesquisa de diferentes culturas e matrizes civilizatórias no âmbito do marco do reconhecimento e horizontalidade. Ou seja, todo o conhecimento tem uma mesma hierarquia e a mesma validade (GUARACHI, 2010).

A raiz da Conferência sobre o Desenvolvimento Sustentável e Diversidade Bio-Cultural organizado pela Universidade de Genebra/Suíça, em Dezembro de 2006, foi reconhecido os saberes dos povos como cientistas. Neste primeiro Seminário Internacional, participaram cientistas, ativistas e líderes indígenas camponeses de todo as partes do mundo, todos comprometidos e empenhados a encontrar e implementar novos paradigmas de desenvolvimento e de ciências. A contribuição substancial está na comprovação de que o local do conhecimento é eventualmente universal, por existir em contextos diferentes e de ecossistemas da América Latina e do mundo, mais semelhanças do que diferenças em seus princípios saberes, tecnologias e técnicas.

O intercâmbio de experiências na execução dos projetos de desenvolvimento sustentável como uma interface para o "Viver Bem" (assim ele foi chamado na Bolívia), seminários, oficinas e publicações (compartilhadas na revista COMPAS e outras de circulação em espanhol e inglês) permitem abrir nossas mentes e corações, aos nossos irmãos da Índia, Sri Lanka, na Ásia e no Gana, Zimbábue, Nigéria, Quênia e África do Sul. A busca por uma abordagem teórica, conceitual e metodológica e que possa fortalecer as epistemologias do Sul, deve permitir a complementaridade entre a sabedoria das nações indígenas originárias e camponesas e o conhecimento científico ocidental moderno de origem eurocêntrica para a sustentabilidade alimentar como uma condição prévia para a segurança e soberania alimentar e desenvolvimento sustentável.

Isso significa adotar um enfoque evolutivo e plural, aberto ao diálogo de saberes e às mudanças de paradigmas, em que o resultado é um processo com várias fases que vão desde a agricultura orgânica, agroecologia, a revalorização do saber e da sabedoria das nações indígenas originárias, até o desenvolvimento sustentável do "Viver Bem". É importante notar que o diálogo intercientífico busca a complementaridade de saberes, percepções e maneiras de gerar conhecimento. No entanto, acreditamos que as ciências ocidentais de origem eurocêntrica (naturais, sociais, convencionais ou alternativas) também possuem algo de instrumental sendo portanto, fundamental no âmbito da ontologia e epistemologia das ciências dos povos indígenas originários camponeses. 
O diálogo de saberes não é um enfoque eclético ou a síntese de uma contradição, mas sim corresponde à lógica do terceiro incluído. A este respeito, é importante estabelecer algumas características das ciências dos povos indígenas originários e encontrar as "pontes epistemológicas" com a ciência ocidental, particularmente as ciências sociais inscritas no paradigma qualitativo, da ciência holística, das ciências paranormais e as mal denominadas etnociências.

\section{O Projeto de Pesquisa: "Rumbo a la sostenibilidad alimentaria - Reconfigurando la interacción de sistemas alimentarios en Sudamérica y África”}

O ponto de partida do projeto "Rumbo a la sostenibilidad alimentaria - Reconfigurando la interacción de sistemas alimentarios en Sudamérica y África”, reside no aumento da atenção global que o tema da segurança alimentar tem recebido após o colapso da infraestrutura financeira global em 2007 e 2008 que - entre outras coisas - teve um rápido aumento dos preços dos alimentos em nível mundial, colocando milhões de pessoas em graves problemas de insegurança alimentar.

Mas, enquanto o projeto se concentra em trabalhar aspectos que foquem em ações de como melhorar a segurança alimentar, também se busca construir um quadro conceitual e metodológico que considere o problema da segurança alimentar mais do que simplesmente aumentar a oferta em termos de quantidades de alimentos. A fome e a insegurança alimentar estão enraizadas em uma distribuição desigual no que diz respeito ao acesso aos recursos naturais, humanos e financeiros de bilhões de pessoas que sofrem de insegurança alimentar. Isso significa que o projeto começa com uma abordagem mais ampla para a segurança alimentar, que visa uma melhor compreensão das complexas interações entre os diferentes sistemas de alimentos e seus efeitos sociais, econômicos, políticos e ecológicos - e agir com esse entendimento - requer ver a segurança alimentar como um conceito mais amplo de sustentabilidade alimentar.

Isso significa, não apenas perguntar se as pessoas têm comida suficiente em termos de disponibilidade, acesso e utilização biológica que é o conceito de segurança alimentar usado pela FAO e muitos outros; mas também significa perguntando sobre os efeitos positivos e negativos que alguma forma de produzir e, posteriormente processar, distribuir e consumir. Considera os aspectos da justiça social e ambiental. Considera as condições nas quais os alimentos são produzidos, processados, distribuídos e consumidos, exige aplicar o enfoque de sistemas alimentares.

Consequentemente, o projeto analisa diferentes sistemas alimentares, considerando o conceito de sustentabilidade alimentar, baseada em cinco princípios: "la seguridad alimentaria, el derecho a la alimentación, la reducción de pobreza y desigualdad, el desempeño ambiental y la 
resiliencia socio-ecológica." Estes princípios são os fundamentos normativos que orientam a identificação de inovações e opções políticas para tornar os sistemas alimentares mais sustentáveis, tanto em suas estruturas internas e sua coexistência e interações, como mostrado na Figura 2.

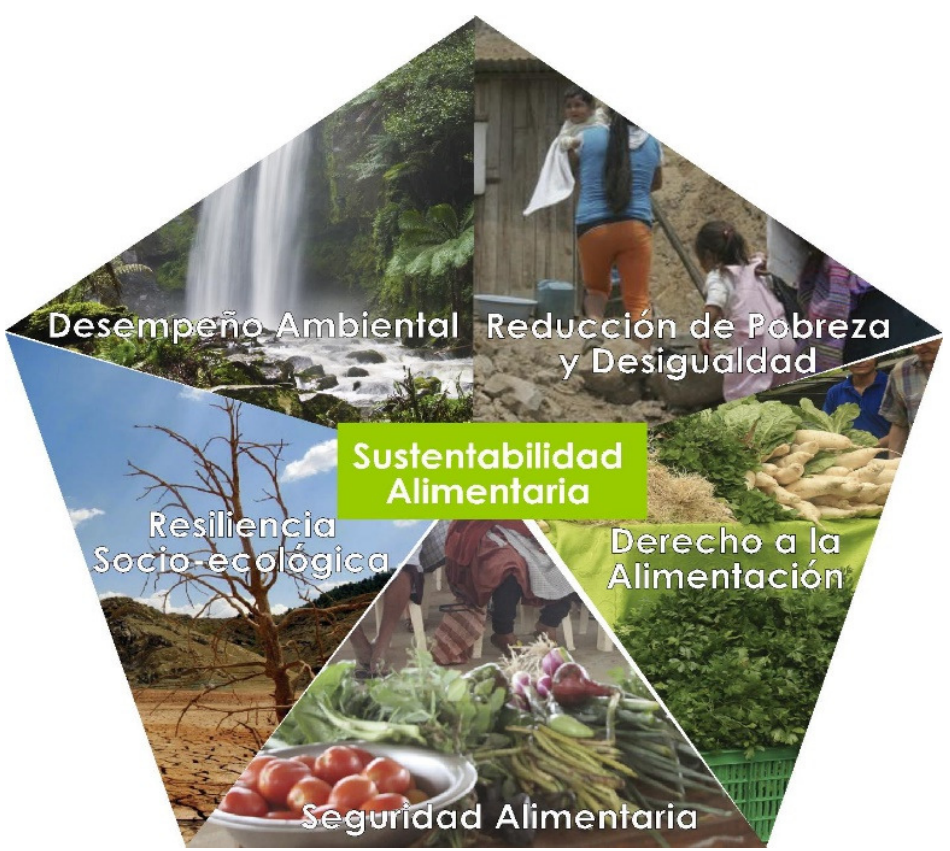

Figura 2. Esquema de los cinco pilares del concepto de la sustentabilidad alimentaria Fonte: Os autores, 2016.

O projeto adota uma abordagem de pesquisa transdisciplinar, já que esta é uma das maneiras mais eficazes para lidar com as complexidades e incertezas que devem ser consideradas quando se investiga os fatores que moldam a sustentabilidade dos sistemas alimentares. $\mathrm{O}$ enfoque transdisciplinar significa organizar um processo de coprodução de saberes entre pesquisadores e pesquisadoras e outros atores interessados no sistema alimentar. Isso inclui a produção de conhecimentos, meta ou normativas (expressos nos cinco princípios de sustentabilidade alimentar), o conhecimento dos sistemas (compreensão dos sistemas alimentares em termos de questões de pesquisa) e o conhecimento de transformação (identificação de inovações e opções políticas para melhorar a sustentabilidade dos sistemas alimentares).

A produção ou transformação do conhecimento está intimamente relacionado com a 
estratégia de comunicação e implementação do projeto e dos resultados da pesquisa. Ela é organizada em torno do desenvolvimento de um "Marco de Evaluación de Sustentabilidad Alimentaria” (MESA ou FoodSAF pela sua sigla em Inglês) que pode ser usado pelos atores nãoacadêmicos para avaliar a sustentabilidade alimentar dos sistemas alimentares de interesse e, assim, encontrar inovações e opções políticas para tornar os sistemas alimentares mais sustentáveis.

A equipe de pesquisa reúne profissionais da geografia humana e física, antropologia social, estudos jurídicos, economia (política), agroecologia, agronomia e nutrição. Antes do início do projeto, foram realizados quatro oficinas com as distintas organizações interessadas na Suíça, na Bolívia e no Quênia, em que os participantes concordaram que a sustentabilidade alimentar é o conceito central do projeto de pesquisa. Também houve um consenso de que as regiões de estudos de casos seriam definidas na Bolívia e no Quênia. A seleção destes dois países como estudos de caso baseou-se nos seguintes critérios:

1) Se a vulnerabilidade à insegurança alimentar é grave;

2) Se a implementação do direito à alimentação está avançado (grau de reconhecimento do direito à alimentação em nível nacional);

3) Se há colaboração de longo prazo entre as instituições de pesquisa dos dois países com a Universidade de Berna, Suíça.

No Quênia, os participantes da oficina preparatória organizada março 2014 identificaram na região do Monte Quênia como uma área de estudo para o desenvolvimento do projeto. Mais especificamente, a pesquisa é conduzida nos municípios Laikipia e Meru. Nesta região, as grandes culturas comerciais empregam milhares de trabalhadores agrícolas, que ao mesmo tempo são os pequenos produtores. Além disso, existem outros produtores de alimentos na região, incluindo grandes fazendas de pequenas e médias explorações agrícolas. Estes sistemas alimentares coexistentes produzem e processam parcialmente, comercializam e consomem seus alimentos em uma paisagem caracterizada como um mosaico. Estas paisagens cobrem uma ampla gama de zonas agroecológicas com terras úmidas e semi-úmidas, além de dispor também de regiões semi-áridas e áridas. Também, estão conectados com os mercados locais, nacionais e globais. Produzem culturas comerciais (chá, café, trigo, algodão, banana, manga e flores); e culturas alimentares destinadas ao autoconsumo (milho, feijão, legumes, batatas, tomates e cebolas), além dos produtos agrícolas (leite e carne de gado, cabras e camelos).

Os sistemas alimentares diferentes na região disputam terras, recursos e água, o acesso à água vem sendo, cada vez mais disputado. Com base em diferentes zonas agroecológicas e 
diversidade cultural (por exemplo, Meru, Kikuyu, Embu, Boran e outros), a região do Monte Quênia é muito adequado para comparação com outras regiões do Quênia e países vizinhos. A pesquisa com outros temas relacionados vem sendo realizado há muitos anos na área de CETRAD e da CDE, bem como outras organizações da região que podem servir de base para o estudo.

$\mathrm{Na}$ Bolívia, os participantes da oficina preparatória selecionaram a área de Santa Cruz como um caso de estudo. No mosaico da região, coexistem sistemas alimentares de pequenos agricultores indígenas camponeses, agricultores migrantes da região Andina, juntamente com outros sistemas alimentares envolvendo produtores e atores de grande e média escala, que por sua vez estão diretamente envolvidos na transformação, distribuição e consumo alimentos.

A cultura principal é a soja. Cerca de $97 \%$ dos 12.000 produtores de soja na região são produtores de pequena e média escala, que também produzem milho, vegetais, cana-de-açúcar e arroz. Os $3 \%$ restantes, são os que mais acessam os créditos, isto é, são grandes produtores que cultivam 55\% da área total da região com soja e se beneficiam dos subsídios diesel e da rápida expansão da infra-estrutura industrial e de transporte, relacionadas com o cultivo de alimentos e cultura flexível.

Ambas as regiões, o Departamento de Santa Cruz na Bolívia e na região noroeste do Monte Quênia no Quênia são importantes para a segurança e soberania alimentar regional e nacional. Ao mesmo tempo, se observam rápidas mudanças que provocam perturbações nos sistemas e atividades agroalimentares locais, impactando o meio ambiente, os meios de subsistência das populações locais e afetando processos de urbanização rurais observados. Em ambas as regiões identificamos exemplos para os cinco sistemas alimentares definidos por Colonna et al. (2013), sendo selecionados três na Bolívia e três no Quênia para serem estudados no projeto:

O sistema agroindustrial é importante nas duas áreas de estudo e por essa razão foi selecionado tanto na Bolívia, como no Quênia. No Quênia, envolve a produção e comercialização de hortaliças e conecta a região com os consumidores na Europa. De acordo com o Plan de Desarrollo Municipal de San Pedro, na Bolívia 82,5\% da área é cultivada no verão com soja e 77,6\% no inverno, sendo majoritariamente para exportação.

O Quênia também foi selecionado por possuir um sistema regional que abarca a cadeia agroalimentar de milho e carne, principalmente composta por pequenos e médios produtores. Eles são parte de uma grande rede de atores nas áreas de produção rural nos municípios de Meru e Laikipia e os atores que vivem em áreas urbanas e peri-urbanas que estão envolvidos no processamento, comercialização, distribuição e consumo de alimentos nas capitais regionais de 
Meru e Nanyuki, na cidade de Nyeri e na capital Nairobi.

O terceiro sistema em estudo no Quênia é um sistema alimentar local que compreende uma cadeia agroalimentar curta de produtores, processadores artesanais, comerciantes e consumidores de milho, batatas, frutas e legumes nas comunidades de Timau em Meru. Representa uma parte significativa do setor empresarial local informal que conecta as famílias de pequenos produtores com os mercados locais.

Além do sistema agroindustrial, um sistema alimentar nacional de alimentos na Bolívia também foi selecionado. O sistema alimentar consiste no povoado Guarani no Chaco de Santa Cruz, tradicionalmente baseado na subsistência e conhecimentos endógenos. Este sistema alimentar abrange, por exemplo, milho, mandioca, amendoim, locoto, feijão, frutas e legumes, mas tem sofrido muitas mudanças por várias razões, sobretudo, como a migração e influências do sistema agroindustrial.

O terceiro sistema alimentar pesquisado na Bolívia é um sistema de alimentação de qualidade diferenciada. É uma iniciativa entre vários produtores que têm crescido bastante nos últimos tempos e vem oferecendo alimentos saudáveis e acessíveis para o público consumidor da cidade de Santa Cruz. Este sistema é caracterizado pela interação de uma rede de produtores agroecológicos, processadores, comerciantes, funcionários municipais, ONGs e organizações de consumidores que partilham de ideias semelhantes.

O processo de diálogo de saberes já começou antes do projeto ser definido, fato que facilitou enormemente a definição dos conceitos e abordagens. Este processo se expressa em diferentes fases. Primeiramente, o problema dos sistemas alimentares e de como a pesquisa foi definida nos grupos focais das diferentes partes interessadas (um grupo no Quênia e um na Bolívia em conjunto com pesquisadores da Suíça).

Em segundo lugar, foram sendo integrados os diferentes pontos de vista das várias disciplinas na forma de "pacotes de trabalho" e juntos se definiram os métodos e os indicadores para analisar os cinco pilares da sustentabilidade alimentar nos distintos contextos. Enquanto o grupo de trabalho 1 se dedicava aos contextos mais amplos das regiões - universo das pesquisas -, os grupos de trabalho 2 e 4 focavam nos fatos mais concretos que dizem respeito aos aspectos sociais, econômicos e ambientais, produzindo assim os conhecimentos necessários para avaliar a sustentabilidade dos sistemas alimentares que estavam sendo pesquisados. O grupo de trabalho 5 executou a principal tarefa - que foi a de integrar todos os resultados dos outros "pacotes de trabalho" de forma que os traduziu nas atividades que estão no núcleo da estratégia de comunicação 
e implementação do projeto, considerando para tal a sua incidência política.

Terceiro, no processo de pesquisa, foram incluídos diferentes atores nas oficinas. Os conteúdos abordados nas oficinas foram previamente definidos em reuniões entre os pesquisadores e pesquisadoras do projeto e os grupos locais, como por exemplo, no município de Cabezas, o grupo de mulheres Guarani que esteve presente em todos os encontros.

Os temas variaram desde as concepções e visões sobre a alimentação, bem como sobre os direitos das mulheres de resgatarem conhecimentos de plantas medicinais e a preparação de cremes medicinais. Paralelo a isso, alguns pesquisadores e pesquisadoras e agentes locais analisaram a informações das oficinas de trabalho e prepararam encontros para apresentarem e discutirem os primeiros resultados. Nestes encontros, se levou em conta diferentes atores locais, bem como os distintos sistemas alimentares com o objetivo de propor políticas públicas de uma forma conjunta, considerando não apenas a interpretação dos resultados por parte dos cientistas, mas também dos agricultores e agricultoras camponeses e camponesas, processadores de alimentos, vendedores e vendedoras e, por fim, consumidores e consumidoras.

Um tema que saiu deste diálogo foi o suporte do projeto nos processos de elaboração dos Planos Territoriais de Desenvolvimento Integral (PTDI) que todos os municípios devem elaborar, tomando por base as regiões de vida e os sistemas de vida existentes nos municípios. Este novo procedimento se apresenta como uma oportunidade de vincular atividades do projeto com as necessidades dos municípios, complementando às atividades dos pesquisadores e pesquisadoras que estão permanentemente nos três municípios de La Guardia, Cabezas e San Pedro no Departamento de Santa Cruz.

O projeto é gerido por um conselho composto por representantes de diferentes instituições associadas do norte ao sul. O conselho delibera e toma as decisões estratégicas e depois monitora sua implementação.

Ao promover o uso do Marco de Evaluación de Sustentabilidad Alimentaria (MESA), o projeto assegura, de forma efetiva, o intercâmbio e difusão os resultados das pesquisas e os produtos do projeto das partes interessadas que estão além das áreas iniciais dos estudos de caso. Com efeito, muitas das partes interessadas (por exemplo, gestores públicos, organizações da sociedade civil e empresas privadas) não estão interessadas ou não capazes de avaliar a sustentabilidade dos sistemas alimentares por meio de uma pesquisa científica que seja cara ou prolongada.

O uso de um marco de avaliação da sustentabilidade alimentar desenhado para a política e 
prática permitirá uma avaliação menos extensa dos sistemas alimentares. Para otimizar o uso do MESA, o projeto oferecerá orientação de expertos na sua implantação permitindo futuras aplicações, aperfeiçoamento e promoção da ferramenta. Como estes esforços de incluir - desde o início - diferentes saberes, conhecimentos e pontos de vista, o projeto espera nos próximos três anos, se consolidar como uma contribuição para todas as pessoas interessadas em configurar nossos sistemas alimentares e suas interações de uma forma mais sustentável.

\section{Referências}

AGRUCO. Plan Rector de la Fase IX. Documento de trabajo. Cochabamba: AGRUCO, 2011.

AGRUCO. Informe de la Fase VIII. Documento de trabajo. Cochabamba. AGRUCO, 2010.

AGRUCO. Autoevaluación y evaluación prospectiva de la Fase VIII. Documento de trabajo. Cochabamba: AGRUCO, 2010.

AGRUCO. Plan Rector de la Fase VIII del Centro Universitario AGRUCO. Mimeógrafo. 2006.

AGRUCO. Plan Rector de la Fase VII del Centro Universitario AGRUCO. Mimeógrafo. 2004.

AGRUCO. Experiencias colectivas de las comunidades. Revalorización de la sabiduría de los pueblos indígenas originarios de los Andes. Cartillas de revalorización. UMSS, AGRUCO, COSUDE, COMPAS, editores, 2000.

AGUILAR, P. Por un marco teórico conceptual para los estudios de antropología de la alimentación. Anales de antropología. v.35. México, D. F.: Instituto de investigaciones antropológicas de la Universidad Nacional Autónoma, 2011.

CONDARCO, R. Historia de la ciencia y el saber en Bolivia. La Paz, Bolivia: Academia nacional de ciencias de Bolivia, 1981.

CONTRERAS, J. Y GRACIA, M. Alimentación y cultura: Perspectivas antropológicas. Barcelona, España: Ariel S.A. editores, 2005.

D'ADAMO, P. Y WHITNEY, C. Los grupos sanguíneos y la alimentación. Barcelona: Zeta editorial, 1996.

DELGADO, F. Y MARISCAL, J. C. Educación intra e intercultural. Alternativas a la reforma educativa neocolonizadora. Serie cosmovisión y ciências, n. 1. La Paz. COMPASAGRUCO/UMSS. PLURAL Editores, 2006. 
DELGADO, F. El diálogo intercultural e inter-científico: Un nuevo marco teórico para el Desarrollo Endógeno Sustentable y la reforma universitaria. Rev. Agricultura Año 58 n.38. Cochabamba: FCAPyF/UMSS - CIF/UMSS - PROINPA, 2006.

DELGADO, F. Y ESCOBAR, C. editores. Diálogo intercultural e inter-científico. Para el fortalecimiento de las ciencias de los pueblos indígenas originarios. Serie cosmovisión y ciências, n. 2. La Paz: COMPAS - AGRUCO/UMSS. PLURAL Editores, 2006.

DELGADO, F. Agroecología y Desarrollo sostenible Sustentable para Vivir bien. 25 años de las experiencias de AGRUCO. La Paz, Bolivia: CDE - COMPAS - CAPTURED. PLURAL Editores, 2011.

DELGADO, F. Y GUARACHI, G. Chachawarmi para el Suma qamaña. XXVIII Congreso Latinoamericano de Sociología. ALAS. Recife-Brasil, 2011.

DELGADO, F., TAPIA, N. Y RICALDI, D. Diálogo intercultural sobre la vida y la muerte. Serie cosmovisión y ciências, n. 6. La Paz- Bolivia: COMPAS - AGRUCO/UMSS, Plural editores, 2012.

DELGADO, F. Y RICALDI, D. Desarrollo endógeno y transdisciplinariedad en la educación superior: Cambios para el diálogo intercientífico entre el conocimiento eurocéntrico y el conocimiento endógeno. Serie cosmovisión y ciências, n.5. La Paz- Bolivia: Plural editores, 2012.

DELGADO, F. Y DELGADO, M. Vivir y comer bien en los andes bolivianos: Aportes de los sistemas agroalimentarios y las estrategias de vida de las naciones indígenas originarias campesinas a las políticas de seguridad y soberanía alimentaria. La Paz- Bolivia: FAO, AGRUCO-UMSS-FCAPyF, FI y Plural editores, 2014.

ESCOBAR, C. Innovaciones metodológicas para el diálogo intercultural e intercientífico: La perspectiva transdisciplinar y el enfoque intermetodológico. Mimeógrafo. 2006.

DUSSEL, E. La China (1421 - 1800) Razones para cuestionar el eurocentrismo. UAM Iztapalapa - México, 2004. Disponível em www.afyl.org

FEYERABEND, P. Contra el método. Barcelona - España: Ed. Ariel, 1976

GACETA OFICIAL DE BOLIVIA. Plan de Desarrollo Económico y Social 2016-2020 en el Marco del desarrollo Integral para Vivir Bien, Ley 786, La Paz (9 marzo de 2016), 2016.

GACETA OFICIAL DE BOLIVIA. Ley marco de la madre tierra y el desarrollo integral para vivir bien, Ley 300, La Paz (15 octubre de 2012), 2012.

GACETA OFICIAL DE BOLIVIA. Ley de educación Avelino Siñani y Elizardo Perez, Ley 070, La Paz (20 diciembre de 2010), 2010.

GACETA OFICIAL DE BOLIVIA. Ley de la Revolución Productiva. Comunitaria, Agropecuaria, Ley 144, La Paz (26 junio de 2011), 2011. 
GACETA OFICIAL DE BOLIVIA. Ley de Organizaciones económicas campesinas, indígena originarias - OECAS y de Organizaciones económicas comunitarias - OECOM, Ley 388, La Paz (28 enero de 2013), 2013.

GACETA OFICIAL DE BOLIVIA. Ley de Derechos de la Madre Tierra, Ley 071, La Paz (21 diciembre 2010), 2010.

GACETA OFICIAL DE BOLIVIA. Constitución política del Estado Plurinacional de Bolivia, La Paz (7 febrero de 2009), 2009.

GUARACHI, G. El pluralismo comunitario inter-civilizatorio boliviano: Resquebrajando la modernidad y auspiciando el encuentro con la ancestralidad en el tiempo - espacio actual. V Congreso Nacional de Sociología. Cochabamba - Bolivia, 2010.

HAVERKORT, B., DELGADO, F., SHANKAR, D. Y MILLAR, D. Hacia el diálogo intercientífico. Construyendo desde la pluralidad de visiones de mundo, valores y métodos en diferentes comunidades de conocimiento. La Paz, Bolivia: Plural editores, 2013.

HUANACUNI, F. Alimentación digna y con dignidad. AGRUCO. Cochabamba, Bolivia, 2013.

KUHN, TH. La estructura de las revoluciones científicas. 8 Edición. México: Fondo de cultura econômica, 2004.

MORFAUX, L. M. Diccionario de Ciencias Humanas. Grijalbo. Barcelona-Buenos AiresMéxico, 1985.

RIST, S.; DELGADO, F. Strengthening endogenous knowledge production through intercultural dialogue. In: Rural Extension Manual. p.346-353. 3a Ed. 2009.

RIST, S. Y WIESMANN, U. Mythos, Lebensalltag und Wissenschaft im Berggebiet - eine Einführung, p. 159-169, In F. Janneret, Wastl-Walter, D., Wiesmann, U., Schwyn, M., ed. Welt der Alpen-Gebirge der Welt, Ressourcen, Akteure, Perspektiven. Paul Haupt, Bern, 2003.

SACHS, W. Diccionario del desarrollo. Una guía del conocimiento como poder. PRATEC. Lima-Perú, 1996.

SALAZAR, M.C. (Ed.) La investigación - acción participativa. CEAAL. Madrid - España: Universidad Nacional de Colombia - OEI. Editorial Popular, 1992.

SAN MARTÍN, J. Uk'amäpi: En la búsqueda del enfoque para el Desarrollo Rural Autosostenible. Serie La vida en las comunidades. AGRUCO, n.1. Cochabamba-Bolivia, 1997.

SEVILLA, G. E.; ALONSO, M. A. Para una teoría centro-perifería desde la Agroecología. In: ANAIS: Congreso de la sociedad española de agricultura ecológica, p. 448-460. Toledo, España, 1994. 
SOLER, M. El contexto socioeconómico de la agricultura ecológica: La evolución de los sistemas agroalimentarios. Curso de experto universitario en producción agrícola. Universidad de Sevilla, departamento de economía aplicada. Sevilla, España. (mimeo), 2004.

VARGAS, F. Y DELGADO, F. Reforma Universitaria y Educación intra e intercultural: Hacia un nuevo paradigma de la educación superior en Bolivia y Latinoamérica. Mimeógrafo, 2005.

Artigo recebido em 29/08/2016. Autores convidados. 